\title{
Review Article \\ Mechanisms Regulating Stemness and Differentiation in Embryonal Carcinoma Cells
}

\author{
Gregory M. Kelly $1,2,3,4,5,6$ and Mohamed I. Gatie ${ }^{1,2}$ \\ ${ }^{1}$ Department of Biology, Molecular Genetics Unit, Western University, London, ON, Canada \\ ${ }^{2}$ Collaborative Program in Developmental Biology, Western University, London, ON, Canada \\ ${ }^{3}$ Department of Paediatrics and Department of Physiology and Pharmacology, Western University, London, ON, Canada \\ ${ }^{4}$ Child Health Research Institute, London, ON, Canada \\ ${ }^{5}$ Ontario Institute for Regenerative Medicine, Toronto, ON, Canada \\ ${ }^{6}$ The Hospital for Sick Children, Toronto, ON, Canada \\ Correspondence should be addressed to Gregory M. Kelly; gkelly@uwo.ca and Mohamed I. Gatie; mgatie@uwo.ca
}

Received 30 October 2016; Revised 10 January 2017; Accepted 8 February 2017; Published 8 March 2017

Academic Editor: Jijun Hao

Copyright (C) 2017 Gregory M. Kelly and Mohamed I. Gatie. This is an open access article distributed under the Creative Commons Attribution License, which permits unrestricted use, distribution, and reproduction in any medium, provided the original work is properly cited.

\begin{abstract}
Just over ten years have passed since the seminal Takahashi-Yamanaka paper, and while most attention nowadays is on induced, embryonic, and cancer stem cells, much of the pioneering work arose from studies with embryonal carcinoma cells (ECCs) derived from teratocarcinomas. This original work was broad in scope, but eventually led the way for us to focus on the components involved in the gene regulation of stemness and differentiation. As the name implies, ECCs are malignant in nature, yet maintain the ability to differentiate into the 3 germ layers and extraembryonic tissues, as well as behave normally when reintroduced into a healthy blastocyst. Retinoic acid signaling has been thoroughly interrogated in ECCs, especially in the F9 and P19 murine cell models, and while we have touched on this aspect, this review purposely highlights how some key transcription factors regulate pluripotency and cell stemness prior to this signaling. Another major focus is on the epigenetic regulation of ECCs and stem cells, and, towards that end, this review closes on what we see as a new frontier in combating aging and human disease, namely, how cellular metabolism shapes the epigenetic landscape and hence the pluripotency of all stem cells.
\end{abstract}

\section{Introduction}

We have just celebrated the 10th anniversary of the TakahashiYamanaka report on induced pluripotent stem cells, where introducing four transcription factors (Oct4, Sox2, Klf4, and c-Myc) was sufficient to reprogram fibroblasts towards pluripotent stem cells [1]. Although this work is a milestone in itself, paving the way for research into furthering our understanding of development and disease $[2,3]$, we must be reminded that most of the investigations into embryonic stem cells (ESCs) and cancer stem cells (CSCs) were preceded by those that focused on teratomas and teratocarcinomas [4-10]. The history is attention-grabbing, as over the last two thousand years teratomas have been attributed to everything from lucky omens, consorting with demons and the devil, participating in inappropriate sexual behavior, and incomplete twinning $[5,11]$. Depending on the source, we know the word is derived from the Greek terato(s) [12], teras [13], or teraton [14] meaning monster and oma from onkoma or swelling [15] and was first reported in the mid-1860s by Rudolf Virchow [16]. Teratomas, which are benign germ cell tumors that contain cells derived from one or more of the three germ layers, develop spontaneously in the testes of the 129 family of inbred mouse strains, or they can be induced in adult mice when the genital ridges of embryos or early embryos themselves are ectopically transplanted into the testes or kidney $[17,18]$. How teratomas develop has been the topic of much debate and is well beyond the scope of this review. However, we would be remiss if we did not note the recent findings that Cyclin D1, a target of canonical $\mathrm{Wnt} / \beta$-catenin signaling, plays a key role in predisposing germ cells to switch their developmental potential to form 
teratomas containing somatic tissues [19]. These teratomas represent "an intersection of pluripotency, differentiation and cancer biology" [20]. Teratocarcinomas contain early embryo-like cells called embryonal carcinoma cells (ECCs) that share three distinct features: (1) they are malignant; (2) they can differentiate into any of the three germ layers or extraembryonic tissue; and (3) they can develop normally when injected into the blastocyst [21, 22]. Although ECCs cells can be propagated following transfer of individual cells [23], the ability to culture them in vitro and their loss of "multipotentiality" [24] set the stage for the studies that followed. Pioneering work by Ralph Brinster, Richard Gardner, Michael McBurney, Beatrice Mintz, Virginia Papaioannou, and many others recognized the importance of ECCs, and their ability as noted by François Jacob, to adopt a normal fate when injected into host mouse blastocysts $[25,26]$. In those early days, many were not fully aware that the attributes of these in vitro model systems would be so instrumental in contributing to studies that delved into trying to understand how ESCs and CSCs remain in a pluripotent state and how intrinsic and extrinsic factors reverse the ability of these cells to self-renew to allow them to differentiate into new lineages. In fact, the suggestion that the genetics of ECCs would uncover genes involved in stem cell self-renewal and pluripotency [27] only serves to underscore the importance of ECC lines. These lines have been and continue to be studied extensively [28-31], and although similarities and differences exist between them, as well as between ECCs and those representative of ESCs and CSCs, this review will focus almost exclusively on two ECC lines from mouse (F9 and P19) and one from human (NTERA-2) and how various pathways influence their pluripotency state. In light of the considerable number of studies generated using these lines, especially in regard to differentiation, which warrants its own review and has been presented in part for P19 cells [32], we have purposely concentrated our efforts to highlight what has been learned about self-renewal and pluripotency from ECCs, and in some cases how these studies have extended to ESCs and CSCs.

\section{Embryonal Carcinoma Cells}

The utility of ECCs as a proxy for the study of early mammalian development and neoplasia was recognized long before we began asking questions regarding pluripotency and self-renewal [4, 33, 34]. Not only were these early studies instrumental in uncovering many of the in vivo mechanisms that govern development [35], but also they led to the widely accepted theory on the process of cancer development [31].

2.1. F9 Teratocarcinoma Cells. F9 teratocarcinoma cells, one widely used mouse ECC line developed from another teratocarcinoma [36], give rise to tumors consisting almost exclusively of undifferentiated cells $[21,37,38]$. F9 cells exhibit a pseudodiploid karyotype composed of 38 acrocentric and 1 metacentric chromosomes, and a G1 and S phase of approximately 8 hours [37]. Once considered nullipotent, as they have lost the ability to differentiate spontaneously [37], studies would later reveal that F9 cells are capable of differentiating into extraembryonic endoderm-like cells $[39,40]$, and evidence would indicate that they share many characteristics of ESCs [41]. Subsequent studies reported that F9 cells can be induced by all-trans retinoic acid (RA) [42], a natural derivative of vitamin A (retinol), thus setting the stage for a plethora of studies to follow [43].

2.2. P19 Cells. P19 cells, another mouse ECC line, were derived from a 7.5-day post coitum embryo that was transplanted into the testis of an adult mouse [44-46]. These cells, which represent a population at a later stage of development than the F9 cells [38], are pluripotent and resemble epiblast stem cells. P19 cells have a male euploid karyotype (40 and XY), and much like F9 cells are considered nullipotent [47]. P19 cells can differentiate into neurons, glial cells, and fibroblasts when treated with RA or into skeletal and cardiac muscle when treated with DMSO [32, 48-52]. While many studies have shed light on the similarities between F9 and P19 cells, details would eventually emerge to indicate that differences in gene regulation allow them to break from pluripotency and differentiate [53-55]. For instance, F9 cells have greater reprogramming capabilities than P19 cells, and this is probably due to differences in the levels of the master pluripotency gene Sox2.

2.3. NTERA-2 Cells. While most studies with ECC lines have focused on those of mouse origin, the NTERA-2 cell line is a human ECC line first established in the 1980s from a testicular teratocarcinoma from a 22-year-old Caucasian male [56]. NTERA-2 cells exhibit a hypotriploid karyotype with a modal chromosome number of 63 [57]. NTERA-2 cells, like mouse ECCs, respond to RA and differentiate towards a neural lineage [5, 58-67]. Furthermore, NTERA-2 cells differentiate into nonneural epithelial cells when treated with bone morphogenic protein-2 (BMP-2), whereas 27X-1 cells, another human ECC line, differentiate into extraembryonic endoderm when exposed to BMP-2 or RA [68, 69]. It is obvious that differences within ESCs [70] and ECC lines exist (Table 1); however, one unifying concept is in their ability to respond to RA, which leads to a loss of pluripotency factors resulting in differentiation towards certain lineages.

\section{Retinoic Acid: Lessons from the Inducer}

RA is a potent teratogen and an important endogenous regulator of proper and extraembryonic endoderm [71]. RA signaling has many diverse roles in the differentiation of ECCs $[72,73]$, most often leading to extraembryonic endodermlike lineages, which in itself has led to the derivation of the extraembryonic-like ECC lines PYS2 and END2 cell [74]. RA-induced differentiation is accompanied by changes in gene expression in F9 cells [75-80], P19 cells [80, 81], and NTERA-2 cells [82]. Genes on this exhaustive list include $c-M y c[83,84]$ and Int-1 (later renamed Wnt1), which have become the focus of many subsequent cancer-related studies. In the case of $c-M y c$ in P19 cells, its expression following RA treatment follows two transient increases at $3 \mathrm{~h}$ and $48 \mathrm{~h}$, and then it drops below basal levels by $144 \mathrm{~h}$ [83]. In contrast, $c-M y c$ expression in $\mathrm{F} 9$ cells declines with RA-induced 
TABLE 1: Key features of ECC lines.

\begin{tabular}{lcccc}
\hline & F9 cells & P19 cells & NTERA-2 cells & References \\
\hline Origin & Mouse & Mouse & Human & {$[37,38,57]$} \\
Colony morphology & Compact & Flat & Flat & {$[37,38,57]$} \\
Global methylation & Hypomethylated & Hypomethylated & Hypermethylated & {$[234,248$,} \\
& Oct4, Sox2, & Oct4, Sox2, & Oct4, Sox2, Nanog, & $255]$ \\
Stemness genes & Nanog, Klf4, Rexl, & Nanog & Dnmt3b, Fff4, Rexl, & {$[58,75-$} \\
& $c-M y c$ & Dppa5 & $77,81]$ \\
LIF requirement & No & No & No & {$[122,149]$} \\
RA-responsiveness & Yes & Yes & Yes & {$[37,38,59$,} \\
Reprogramming efficiency & High & Low & Low & $72]$ \\
Teratoma formation & High & High & High & {$[41]$} \\
Chimera contribution & High & High & No data available & {$[22,26]$} \\
X chromosome status & X:0 & Male & Male & {$[37,38,60]$} \\
\hline
\end{tabular}

differentiation [78] comparable to ESCs [85]. We now know c- $M y c$ is downstream of the Wnt targetome [86], but it was the discovery of Wnt1 itself that was exciting to many in the scientific community as it linked Drosophila embryogenesis and the Wingless protein to protooncogenes and cancer [8789]. Later reports have highlighted Wnt1 and other Wnt genes expression during RA-induced differentiation in P19 cells [90-92], F9 cells [78, 93, 94], and NTERA-2 cells [95, 96]. These early discoveries led to the assembly of complex cell signaling pathways and gene networks linked to ECC differentiation, and these were to be the platform that many have since used to identify the crosstalk and autoregulatory loops that exist within and between ECCs and ESCs [97-103]. It is interesting that while many of these studies revealed that RA must repress certain genes during differentiation, little discussion at the time linked these genes to self-renewal and stemness in ECCs. In fact, despite the irony that stemness genes including $c-M y c$ [83, 104-107], Oct3/4 [108-110], and Sox2 [111-113] had already been identified in ECCs, their specific roles in self-renewal and pluripotency would not be elucidated until later [27, 114]. Meanwhile, studies showing expression of genes such as $K-f g f$ and $H s t-1$ [115-117], TGF $\alpha$, and LAMIN A/C [117-121] provided the framework that gene activity was sufficient and necessary to keep ECCs in the pluripotent state. Two genes linked to stemness and pluripotency are Rexl (Zfp42), encoding a zinc finger transcription factor, and Ccnd1, encoding Cyclin D1. Rex1 expression is not detected in undifferentiated P19 cells [122124]; however, it is induced when Nanog is overexpressed $[122,125]$. Similarly, Nanog controls the expression of Ccnd1, as seen when Nanog is depleted or overexpressed in P19 cells [125] and by retinoids in NTERA-2 cells, which promotes the ubiquitination and degradation of Cyclin D1 [67]. In addition to these studies and others involving $c-M y c$ [104, 126-130], Oct4 [110, 131-133], and Sox2 [111, 112], further evidence that pluripotency genes must be developmentally regulated in the early embryo came from reports that Nanog $[134,135]$ and Foxm1 [136] are downregulated in P19 and F9 cells in response to RA treatment. Foxml, a member of the Forkhead box of transcription factors, is an interesting example as we now know it plays pivotal roles in cell proliferation, differentiation, and self-renewal and acts downstream of canonical $\mathrm{Wnt} / \beta$ catenin signaling $[137,138]$. This downregulation of Oct4, Nanog, and Sox2 is also seen in NTERA-2 cells treated with RA [139], which together with reports on the effects of deregulating $c-M y c$ expression [140] and ZNF536, encoding a novel zinc finger protein [141] in F9 and P19 cells, respectively, underscores the importance of activating, regulating, and maintaining self-renewal and pluripotency genes in the undifferentiated state. Thus, while much of the focus was initially on ways to differentiate ECCs, subsequent efforts were underway to identify pluripotency factors that would attenuate differentiation, thereby maintaining stemness.

\section{Pluripotency Factors and Signaling Crosstalk}

4.1. Leukemia Inhibiting Factor (LIF). Differentiating inhibiting activity (DIA)/leukemia inhibiting factor (LIF) produced by feeder cells or medium conditioned by Buffalo rat liver cells can block differentiation and promote stemness [124, 142-144]. Interestingly, ECCs harbor components responsible for LIF signaling $[145,146]$ and can secrete factors that support self-renewal of ESCs, but, unlike ESCs, they can maintain pluripotency in the absence of LIF or feeder layers $[124,147]$. LIF belongs to the IL-6 family of cytokines, which contain IL-11, oncostatin M, ciliary neurotrophic factor, and others [148], all of which can signal through the JAK/STAT3 (Janus Kinase/Signal Transducer and Activator of Transcription) pathway. LIF activation in P19 cells $[149,150]$ blocks endodermal and mesodermal differentiation [114] and potentiates RA-induced neural differentiation [144, 151]. LIF has no apparent effect on NTERA-2 cells [114], and although there was early debate as to whether or not it had an effect on F9 cells [152, 153], recent evidence indicates that it blocks the ability of F9 cells to differentiate towards an extraembryonic lineage when induced by RA [154]. Moreover, STAT3 in F9 cells is regulated by Src-homology protein tyrosine 


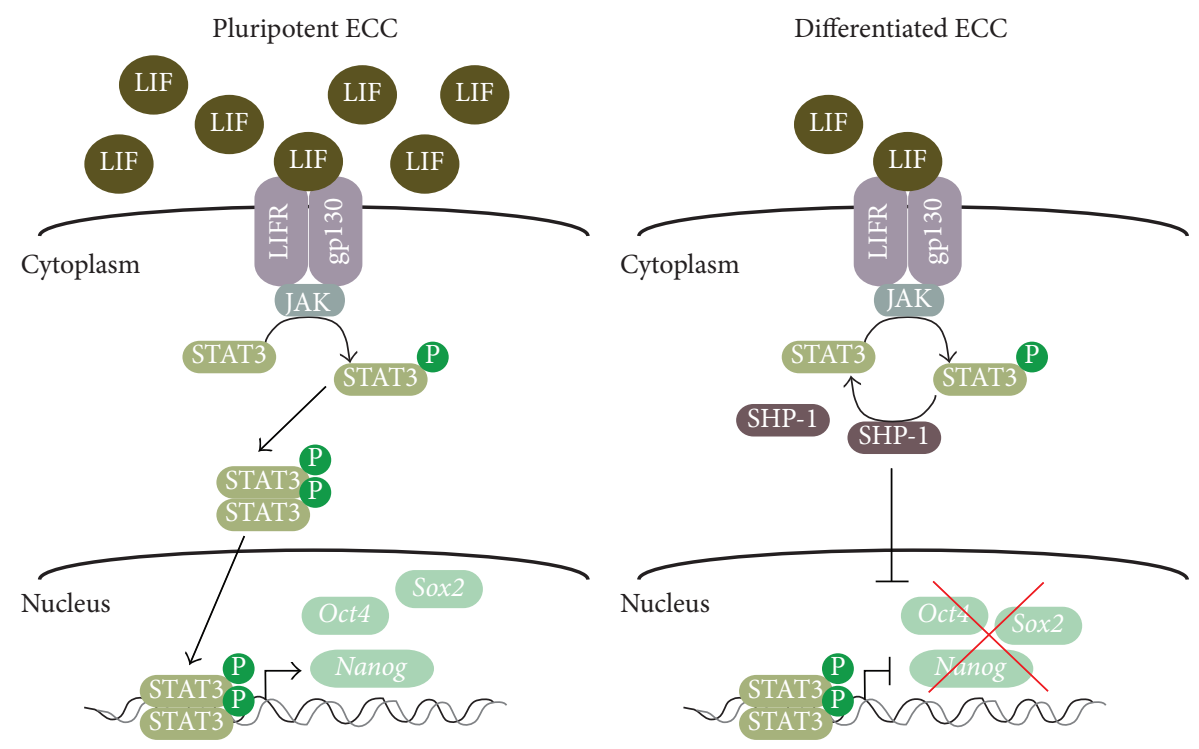

FIGURE 1: LIF signaling maintains ECCs pluripotency. In pluripotent ECC lines, LIF binds to the LIF receptor (LIFR) and gp130 recruiting Janus Kinase (JAK), which in turn phosphorylates and activates Signal Transducer and Activator of Transcription 3 (STAT3). Phosphorylated STAT3 homodimerizes and translocates to the nucleus promoting the expression of pluripotency genes encoding OCT4, SOX2, and NANOG. During differentiation, LIF levels decline substantially leading to decreased phosphorylated STAT3, which is augmented by the tyrosinespecific protein phosphatase SHP-1. The decline in active STAT3 reduces the expression of pluripotency genes.

phosphatase-1 (SHP-1), leading to its dephosphorylation and subsequent decrease in Nanog expression, which, as noted by the authors, restricts the expansion of the epiblast at implantation (Figure 1) [155].

4.2. Nanog. The homeodomain transcription factor Nanog plays an essential role in maintaining stem cell pluripotency and self-renewal. The Nanog promoter is well characterized, and although it is known to contain Oct4 and Sox 2 binding sites, the early studies were contradictory with the report that Oct4 acts alone to induce Nanog expression [156], while another noted that both Oct4 and Sox2 were required [157]. Nanog overexpression in F9 cells maintains them in the undifferentiated state, as evident by the upregulation of Oct4 and SSEA- 1 and downregulation of markers of differentiation including Gata-6, Gata-4, Hnfl $\beta$, and LamininB1 [135]. The Nanog promoter contains one negative and two positive cisregulatory elements that are active in F9 and ES cells, but only one positive element is active in P19 cells [134]. This example not only underscores the complexity of Nanog regulation, but also highlights the differences that exist between ECC lines. Negative feedback loops that regulate ESC pluripotency involving Oct4, FoxD3, and Nanog are known [158]. Furthermore, the presence of one of these loops whereby the Nanog promoter is negatively regulated by its own ectopic expression in ECCs would indicate that the pathway is even more complex than first thought [159]. Similarities in the pathway controlling Nanog expression exist between F9 and P19 cells, but because their Nanog levels differ, as well as Sox2, so too does their pluripotency state $[41,134]$. Nevertheless, Nanog in ECCs is regulated by a Sox 2: Oct4 ratio [159] as well as the interplay between Oct4 and Rexl, which are both involved in the maintenance of self-renewal downstream of Nanog [125].

4.3. Oct4. The crosstalk and feedback within proteins encoded by self-renewal and pluripotency genes are highlighted by the regulation of Oct4, considered as the master regulator of totipotency [160]. Oct4 has many roles in gene regulation, and its own positive and negative regulation is the topic of many studies. For instance, Nspcl, a polycomb protein and a transcriptional repressor that is highly expressed in undifferentiated P19 cells, directly activates the Oct4 promoter [161], which in itself gets negatively regulated following RA treatment [78, 108, 162-165]. Once Oct4 is transcribed and translated in F9 cells, Rex1 expression is upregulated $[166,167]$, and similarly, in P19 cells, the Rex1 promoter is activated by either Oct4 or Sox 2 when Nanog is overexpressed [122]. The Rexl promoter is also activated in differentiated P19 cells when Oct4 is overexpressed [166]. However, while it may seem contradictory, high levels of Oct4 downregulate Rex1 expression in F9 cells [166], which again highlights the importance of the cellular environment and context.

4.4. Wnt Signaling and miRNAs. Although studies indicate that Wnt signaling suppresses pluripotency and promotes differentiation, Oct4 overexpression in P19 cells suppresses canonical Wnt signaling [168]. Nevertheless, canonical Wnt signaling is linked to Oct 4 and pluripotency as evident by the fact that the downregulation of Oct4 expression occurs when T-cell factor 3, Tcf3, serving as a transcriptional repressor in the absence of $\beta$-catenin, is overexpressed in F9 cells (Figure 2) [169]. This supports what was described earlier where Wnt is induced and Axin, a negative regulator of 
TABLE 2: Trend of select miRNAs in P19 and NTERA-2 cells.

\begin{tabular}{|c|c|c|c|c|c|}
\hline \multirow{2}{*}{ miRNA name } & \multicolumn{2}{|c|}{ P19 } & \multicolumn{2}{|c|}{ NTERA-2 } & \multirow{2}{*}{ References } \\
\hline & $\mathrm{P}$ & $\mathrm{D}$ & $\mathrm{P}$ & $\mathrm{D}$ & \\
\hline miR-9 & - & + & - & + & {$[183]$} \\
\hline miR-124 & - & + & - & + & {$[178,179,183]$} \\
\hline miR-125 & - & + & $=$ & $=$ & [179] \\
\hline miR-302 & + & - & + & - & {$[179,180,183]$} \\
\hline Let-7 & - & + & - & + & [181] \\
\hline
\end{tabular}

P: pluripotent ECCs; D: differentiated ECCs

+ : increase, - : decrease, and =: no change in levels.

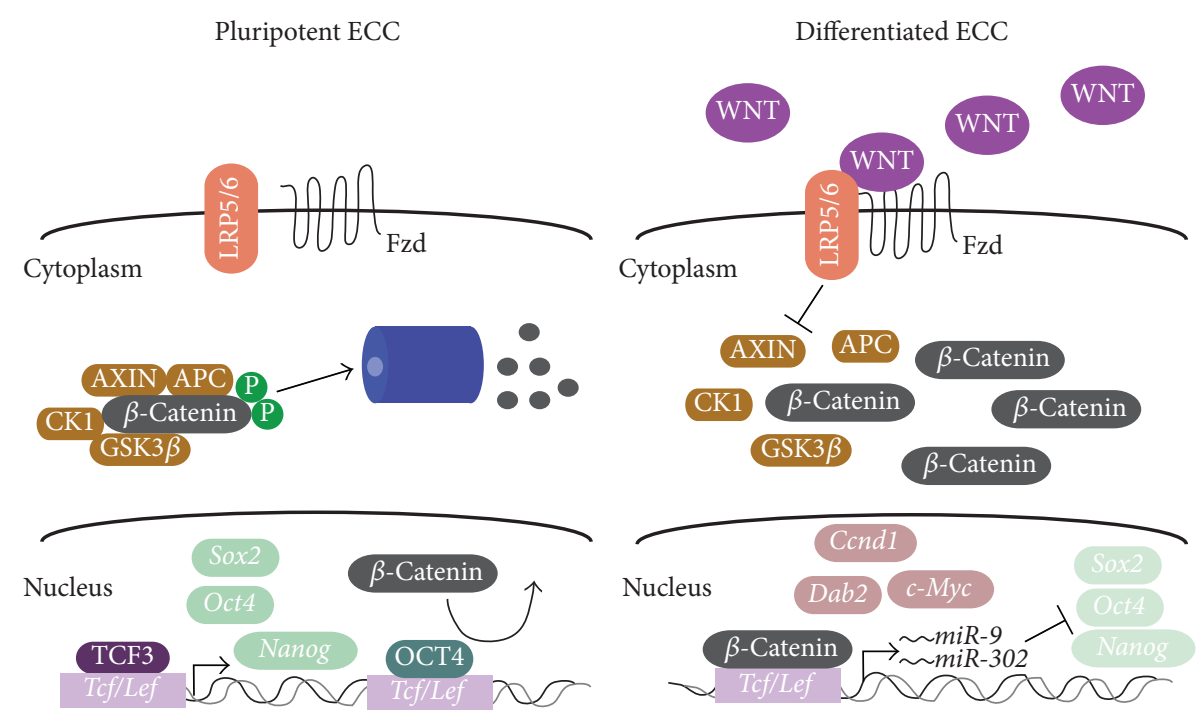

FIgURE 2: The dual role of WNT/ $\beta$-catenin signaling ECCs stemness and differentiation. In the absence of WNT ligand, $\beta$-catenin is phosphorylated and degraded by the proteasome; subsequently, TCF3, a transcriptional repressor of WNT target genes, translocates to the nucleus and upregulates pluripotency genes. TCF3-dependent upregulation of OCT4 allosterically binds to TCF/LEF, preventing $\beta$ catenin from binding, which attenuates WNT signaling and differentiation. In the presence of WNT, AXIN is downregulated leading to the dissociation of the destruction complex, which results in the accumulation of $\beta$-catenin in the cytoplasm and subsequent translocation to the nucleus where it binds to TCF/LEF proteins. As a result, WNT target genes including Dab2, Ccnd1, and $c-M y c$ are upregulated leading to cell differentiation. $\beta$-catenin-TCF/LEF interactions also result in the increase in $m i R-9$ and $m i R-302$ expression, which in turn downregulate the expression of pluripotency genes.

canonical Wnt signaling, declines in RA-treated F9 and P19 cells $[88,91-93,170]$. Another level impacting pluripotency and stemness involves microRNAs (miRNAs), which together with Oct4, Sox2, and Nanog are regulated positively by Wnt signaling (Figure 2) [171]. In one case this regulation involves the mir-302 gene, which encodes a cluster of 5 microRNAs (miRNAs) that are highly expressed in undifferentiated NTERA-2 cells and P19 cells $[172,173]$. Oct 4 can bind directly to $m i R-302$ and upregulate its expression [171], while canonical Wnt signaling regulates mir-302 expression involving 3 TCF/LEF binding sites. In the latter, knocking down $\beta$-catenin leads to decreased expression of mir-302, whereas knocking down Tcf3 produces the opposite effect [174], which promotes the expression of pluripotency genes in F9 and P19 cells $[154,175]$. Other miRNAs play a role in regulating stemness and differentiation of mouse and human ECCs (Table 2), including miR-9, whose expression not only increases with differentiation, but also serves to repress Sox2 in NTERA-2 cells [176]. Other examples include
miR-124, where elevated levels in P19 cells promote neuronal differentiation by suppressing Ezh2, a histone methyltransferase, which represses genes involved in neurogenesis [177]. While many miRNAs are known to impact the ability of ECCs to remain pluripotent [172, 177-182], other modes of regulation, including that by $\mathrm{PI} 3 \mathrm{~K} / \mathrm{AKT}$ signaling, can influence pluripotency and stemness.

4.5. PI3K/AKT Signaling. The PI3K/AKT signaling pathway is well known to have a key role in cell growth, proliferation, metabolism, and survival [183]. This list can be added to as RA and the negative regulation of the Oct4 promoter are accompanied by an increase in AKT signaling in F9 cells [184] and the suppression of PTEN in P19 cells [185]. Furthermore, the phosphorylation of Oct4 and Klf4 by AKT leads to their degradation by the ubiquitin-proteosome system, which promotes the loss of pluripotency in F9 cells [186]. Although RA was previously described as an inducer of differentiation, its presence promotes AKT-dependent 

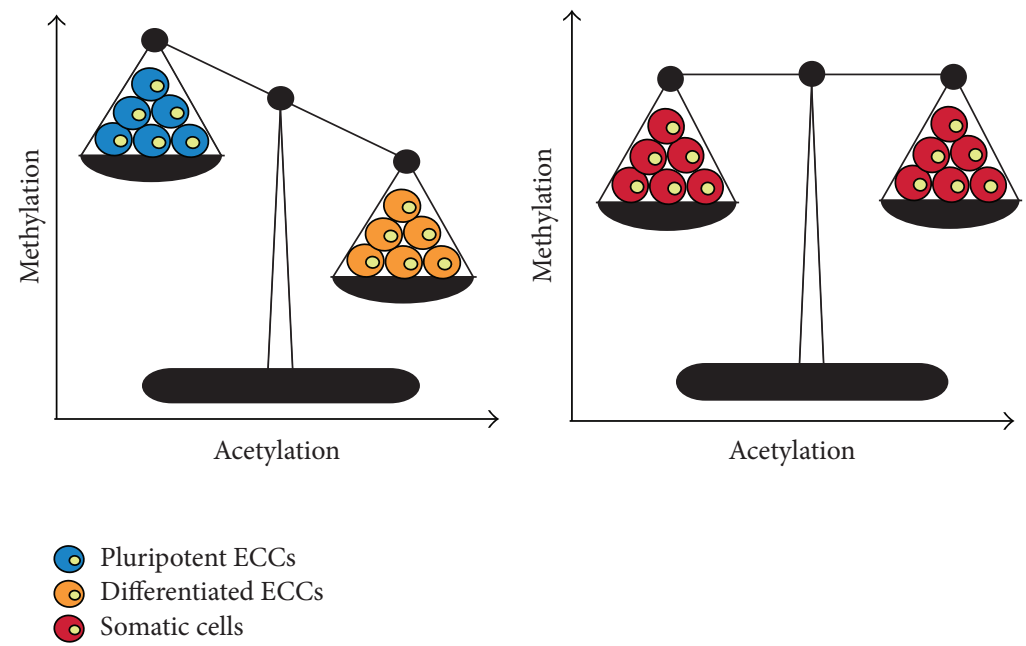

Figure 3: Global methylation and acetylation pattern of ECC lines during stemness and differentiation. Pluripotent ECCs are methylated and deacetylated yielding a low expression profile of differentiation markers. The dimerization of Jun Dimerization Protein 2 (JDP2) results in the recruitment of Histone Deacetylase 3 (HDAC3), which interacts and inhibits Histone Acetylases (HATs) from activating differentiation genes. Pluripotency is lost when DNA methyltransferase 1 (Dnmt1) expression and activity is reduced, resulting in the demethylation of differentiation-inducing genes including Vimentin, Laminin B1, Collagen IV, and Endo A. Similarly, HDAC activity is reduced as the p300 complex displaces the JDP2/HDAC3 complex, resulting in the recruitment of HATs and initiation of c-Jun transcription leading to differentiation.

phosphorylation of the chromatin remodeler SATB1, which binds to SOX2 thereby preventing it from associating with Oct4 to maintain pluripotency. In addition, and contrary to what was described earlier [186], active AKT signaling in P19 cells induces a transient increase in Nanog expression [187], which seems counterintuitive because AKT inhibits pluripotency markers. However, it is more complex than this as Oct4 in ECCs can bind to the human AKT1 promoter, and this is dependent on its phosphorylation state controlled by AKT itself [188]. In fact, these authors found that the stabilization of Oct4 through AKT phosphorylation not only promotes its dissociation from the $A K T 1$ promoter, but also facilitates its interaction with Sox 2 to upregulate Nanog expression. Thus, $\mathrm{PI} 3 \mathrm{~K} / \mathrm{AKT}$ signaling is another means by which pluripotency is dictated in ECCs. However, other mechanisms downstream of signaling pathways such as epigenetic modifications also play a role in regulating stemness and differentiation [189].

\section{Epigenetic Modifications}

Understanding how global changes in gene expression are required to maintain ECCs in a pluripotent state has been a daunting task, one that is nearly eclipsed when considering the roles epigenetic modifiers and chromatin remodelers have on regulating these genes. The complexity imposed by these control mechanisms, especially as they relate to ESC pluripotency and differentiation, is evident by the many recent reviews and their historical account of the field [190-200]. While many epigenetic modifications exist, we will focus on the most common: DNA methylation and histone modifications by acetylation, which intricately link pluripotency genes and microRNAs in germ cell tumor development [201-208] to cancers and other diseases [209-215]. The molecular details of how these modifications occur and the effects imparted by these changes are presented elsewhere [193, 216-219].

5.1. DNA Methylation. Methylation of the fifth cytosine of $\mathrm{CpG}$ islands on the promoter of various genes is conserved in Eukaryotes [220]. Global methylation patterns in somatic cells are relatively stable and well characterized (Figure 3); however, DNA methylation or demethylation is tightly regulated and highly dynamic during embryo development [221, 222]. While multiple studies have highlighted the importance of DNA methylation in the maintenance of stemness and differentiation in ESCs [223-233], some of the first reports were with ECCs.

5.1.1. Methylation, Stemness, and Differentiation. These studies used 5-Azacytidine, which can induce differentiation of various ECCs by inhibiting DNA methyltransferases (DNMTs), though surprisingly not in F9 cells [234-237]. We have seen that F9 cells treated with a DNMT inhibitor do not differentiate and undergo apoptosis instead (unpublished data), which corroborates an earlier report [238]. Therefore, global demethylation in F9 cells is not sufficient to induce differentiation, even though it results in a demethylation profile like that seen following RA treatment [236, 239-241]; however, gene-specific demethylation pattern might vary. The methylation status of any gene can be misinterpreted, as in the case of those involved in the maintenance of pluripotency in F9 cells, which are hypomethylated and therefore transcriptionally active, while those induced with RA, including Vimentin [242], Laminin B1 [243], Collagen IV [244], and Endo B [245], are hypermethylated making them inactive. Furthermore, the promoter of the Thrombomodulin, a marker of differentiation, gene shows a similar methylation pattern regardless of the differentiation status of the F9 
cells. Thus, other mechanisms such as chromatin remodeling may also play a role in gene expression [246]. We know P19 cells treated with RA differentiate towards a neuronal lineage $[49,51]$, and this is marked by global demethylation [247], which is similar to what is seen in F9 cells treated with RA [239]. A reduction in DNMT protein levels and activity leads to reduced global and gene-specific methylation involved in differentiation seen in other ECCs $[237,239,248$, 249]. Specifically in P19 cells, the AP-1 regulatory site in the Dnmtl promoter is heavily methylated in the undifferentiated state [250]. When challenged by 5-Azacytidine, CpG islands upstream of the AP-1 site are demethylated leading to the recruitment of the Jun/Fos complex leading to expression of Dnmt1, which in turn methylates those same sites leading to transcriptional repression [250]. In fact, the methylation of regulatory regions in the Dnmt1 promoter acts in a feedback mechanism, as sensors for the methylation capacity of the cell [250]. While downstream changes to methylation profiles have been linked extensively to pluripotency potential, much less attention has been given to upstream regulators. Early work has emphasized the importance of RAS and its downstream effectors [54, 251] on the role in global and site-specific demethylation by inducing the phosphorylation and activation of c-JUN, which binds to the Dnmt1 promoter, inducing its expression and leading to differentiation [252]. These examples of consistent methylation trends, differences in DNMT activity, and activation of signaling pathways reveal the complexity underpinning the maintenance of stemness and differentiation in ECCs. Although much has been learned regarding the influence of DNA methylation on genes involved in differentiation, we know that similar mechanisms are in place for selfrenewal. For instance, Oct4 and Nanog promote pluripotency in ESCs and ECCs, but it is important to note that the expression of these genes is regulated by methylation. The Nanog promoter in undifferentiated NTERA- 2 cells is methylated $200 \mathrm{bp}$ upstream of Oct $4 /$ Sox 2 binding domains [253]. Similarly, the methylation status of the $c-M y c$ promoter in F9 cells dictates the levels of the protein, which are high in the undifferentiated state but fall precipitously due to RA treatment [130]. This is recapitulated in human ESCs where high c-Myc levels maintain pluripotency in the absence of LIF/STAT3 [254]. Undifferentiated P19 cells maintain high levels of Oct4 expression by promoting a low methylation profile on the Oct4 locus $[255,256]$. Taken together, these studies would indicate that the ratio of demethylation-tomethylation dictates the expression of pluripotency genes in ECCs, and thus the maintenance of stemness $[255,256]$. If so, this role of methylation status could account for the heterogeneity in pluripotency as others and we have noted in ECCs populations.

5.2. RA Signaling and Methylation. While overwhelming evidence was presented earlier that RA induces ECCs differentiation, it is necessary to devote a brief description on how RA and retinoid synthesis and transport to their RAR/RXR are linked to the methylation status of promoters. During differentiation, the cellular RA binding protein 1 (CRABP-1) binds to RA and delivers it to RAR/RXR sites on the DNA of target genes [257]. RA induces CRABP-1 in P19 and F9 cells, yet the methylation pattern of its promoter remains unchanged, even in the presence of 5-Azacytidine, which does not induce CRABP-1 expression [258]. Conversely, a methylated Histone $\mathrm{H} 2 \mathrm{~B}$ variant (TH2B) transfected into F9 cells gets demethylated, signifying that there is active histone gene expression in the undifferentiated state [259]. The Th $2 b$ gene, like many other housekeeping genes, maintains a low methylation profile, which is largely due to the protection of CpG islands imparted by the SP1 transcription factor $[260,261]$. Whereas DNA methylation can play a role in transcriptional repression, the activation of the $\mathrm{H}-2 \mathrm{~K}$ gene during differentiation is associated with hypermethylation, and this is evident from studies with 5-Azacytidine, which attenuates $H-2 K$ expression in F9 cells [262]. Since DNA methylation is not easily reversed, gene regulation may be better controlled temporally by the more labile and reversible modifications made to histones.

5.3. Chromatin Remodeling. Eukaryotic DNA with all its modifications is folded into nucleosomes, which are made up of histone octamers. Since resolving the nucleosome structure [263, 264], many histone modifications have been discovered [265-268]. These discoveries have provided us with a great understanding of how changes to chromatin availability directly or indirectly regulate gene expression. Although histone modifications by methylation are known to play a role in chromatin availability [269], we will focus on acetylation modifications in ECCs. In one example, the modification involves histone acetylation of lysine residues via histone acetyl-transferases (HATs), which weaken DNAhistone interactions allowing several proteins to dock and initiate transcription.

5.3.1. Histone Modifications, Stemness, and Differentiation. P19 cells maintained in an undifferentiated state have high levels of nonacetylated histones (Figure 3), but this declines with RA induction [270, 271]. A similar situation occurs in NTERA-2 cells, where regulatory regions of Oct4 and Nanog in differentiated cells are hypoacetylated, leading to the closed chromatin conformation and reduced expression [272]. The expressions of Oct4 and Nanog are influenced by the knockdown of the Brahma related gene, Brgl, encoding a protein present in Brg-containing Switch/Sucrose NonFermentable (SWI/SNF) complexes [273]. In P19 cells, the involvement of Brgl with the promyelocytic leukemia protein maintains an open chromatin conformation of the Oct4 gene [274], whereas RA induces silencing and chromatin remodeling by receptor-interacting protein 140 [72, 274]. This silencing and remodeling displaces Brgl for the Brahma- (Brm-) containing SWI/SNF complex on both the Oct4 and Nanog promoters, thus silencing transcription [275]. Although comparable conditions exist in ESCs [276] this is not a universal phenomenon as histone acetylation near the Nestin locus accompanies RAinduced differentiation in P19 cells [277]. It is interesting to note that $\mathrm{RAR}^{-/-} \mathrm{F} 9$ cells exhibit increased expression of Slc38a and Stmn2, which is normally associated with differentiated F9 cells due to hyperacetylation, suggesting that RA signaling might have a role in regulating histone 
modification [278]. Modifications by histone deacetylases (HDACs) are also intricately linked to RA signaling. HDACs antagonize HATs, as they remove acetyl groups from lysine residues, a modification that restores their positive charge and leads to chromatin stability that is largely associated with transcriptional repression. Jun Dimerization Protein 2 (JDP2) maintains stemness in F9 cells by serving as a transcription factor not only to recruit HDAC3, but also to have it interact and inhibit HATs [279]. During RA treatment, however, the p300 complex displaces JDP2/HDAC3 leading to acetylation, initiating c-Jun transcription and differentiation [280, 281]. Other examples of this regulation are seen with HDAC3 in P19 cells, which inhibits the autoactivation of the neuronal transcription factor NeuroD [270], or in studies using HDAC inhibitors, which show reduced Nanog expression in undifferentiated P19 and F9 cells, and Esrrb, Klf2, and Rex1 in ESCs [282]. Differentiated ECCs treated with an HDAC inhibitor and showing elevated pluripotency markers would suggest that HDAC activity could be largely regulated by the stemness state of a cell [282]. These reports and many others document the importance of HDACs in regulating chromatin availability, but the fact they also physically interact with pluripotency markers including Sox2 [282], Oct4 [283], and Nanog [284] reminds us of their involvement at other levels. In addition to the control conveyed directly by HDACs, chromatin remodeling of pluripotency genes is facilitated by other factors. For instance, in RA-induced differentiation of P19 cells, Nanog repression is the result of Foxal, a member of the forkhead/winged-helix gene family induced by RA, to recruit the transcriptional corepressor Grg3, which belongs to the Gro/TLE/Grg family [285]. This potentiates subsequent recruitment of HDACs, together with Foxal, to deacetylate histone 3 and repress the Nanog locus [285]. This type of multiplex control is not just reserved for Nanog. In differentiated P19 cells, Oct4 expression initially increases, and in cooperation with histone $\mathrm{H} 3$ acetylation it induces Meisla expression, which recruits HDAC1 directly to the Oct4 promoter to subsequently reduce its activity [286]. Examples of this complex interplay between HDACs and other factors are well documented from ESC studies [198, 287, 288], and it would be of interest to investigate whether similar mechanisms are in place in ECCs.

\subsection{RA Signaling and Histone Modification. Since HDAC} deacetylation of key lysine residues on the regulatory regions of the RAR and RXR receptors would lead to their transcriptional repression, it is easy to envision given the network of genes regulated by RA how important this mechanism is to maintaining pluripotency. Butyrate inhibits histone deacetylation and promotes reversible morphological changes to F9 cells, but it does not induce differentiation [289]. Surprisingly, in the presence of cycloheximide, transcript and protein levels of differentiation markers were sustained in butyrate treated F9 cells [290]. Trichostatin A is another HDAC inhibitor that cannot induce P19 cell differentiation by itself but is able to when cells are cotreated with RA [291]. Like butyrate, treatment of Trichostatin A alone induces apoptosis in P19 cells, whereas cotreatment with RA induces RAR/RXRinduced transcription via histone acetylation [291]. In this study, the authors postulate that histone acetylation alone is not sufficient to induce differentiation, but it nevertheless primes ECCs for these events. Although the RAR/RXR response to acetylation plays a limited role during butyrate and Trichostatin A treatment, it more importantly suggests that other mechanisms are likely involved in the maintenance of stemness [292]. For example, CDK-associated Cullin 1 (CAC1), affects RA-induced differentiation by directly binding to RAR $\alpha$, inhibiting its transcriptional activity in P19 cells [293, 294]. In this position, CAC1 recruits HDAC2, which deacetylates RAR2 to promote pluripotency [293]. While we have provided some examples of how epigenetic modifications influence gene regulation, we did not cover the source of cofactors required to induce such changes. The idea that epigenetic regulation is energetically demanding is often overlooked, and for that reason we will complete our discussion by addressing the fact that many of the cofactors involved are provided by cellular metabolism. Thus, the epigenome is intricately linked to the metabolome [295, 296], and any changes to one would be expected to have direct consequences on the other.

\section{Cellular Metabolism}

We begin this section with some of the earliest discussions to spotlight the contribution of the mitochondria and metabolism to pluripotency and stemness [296-299]. Mitochondria have many roles including its most well-known role, to produce ATP, and obligatory production of reactive oxygen species as the by-product of cellular metabolism. In addition, mitochondrial metabolism is linked to calcium signaling and apoptosis, all of which play a part in pluripotency in ESCs [300-303]. During oxidative phosphorylation (OXPHOS) one molecule of glucose generates 38 molecules of ATP, which in comparison to glycolysis generates 2 ATP molecules. Although glycolysis is inherently less efficient than OXPHOS, it does support and promote high cellular proliferation during embryonic development [304, 305], cancer initiation and progression [306, 307], and neurodegenerative disease states [308, 309]. A balance between glycolysis and OXPHOS metabolism has been considered as a "rheostat" for stem cell fate [310], as these processes that generate and utilize metabolites have an impact on changes in epigenetic modifications and cell signaling networks governing the equilibrium between pluripotency and differentiation [311-314]. The majority of ESCs tend to transition towards OXPHOS with differentiation $[315,316]$, although this is not universal [304] as evident in iPSCs derived from fibroblasts that revert to glycolysis [317]. These findings and others only serve to strengthen the argument that the metabolic state of a cell must be considered when discussing stemness and pluripotency, and we are reminded that some of the seminal studies that led to this account were first reported in ECCs in the 1990s.

One such study examined Phosphofructokinase (PFK), a glycolytic enzyme that catalyzes the phosphorylation of fructose-6-phosphate to fructose 1,6-bisphosphate in the presence of ATP. Van Erp and colleagues (1990) reported that undifferentiated P19 cells show preference to $P f k-L$ expression, encoding an isoform that is more sensitive to 


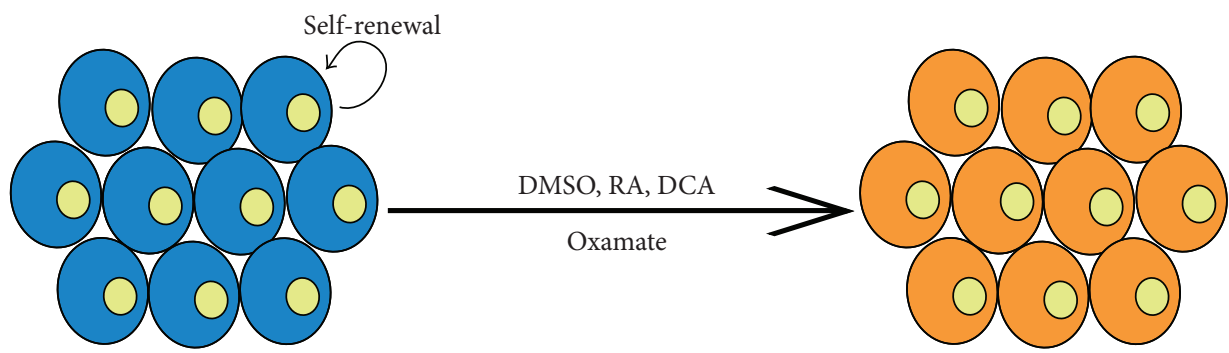

Pluripotent ECCs

Differentiated ECCs

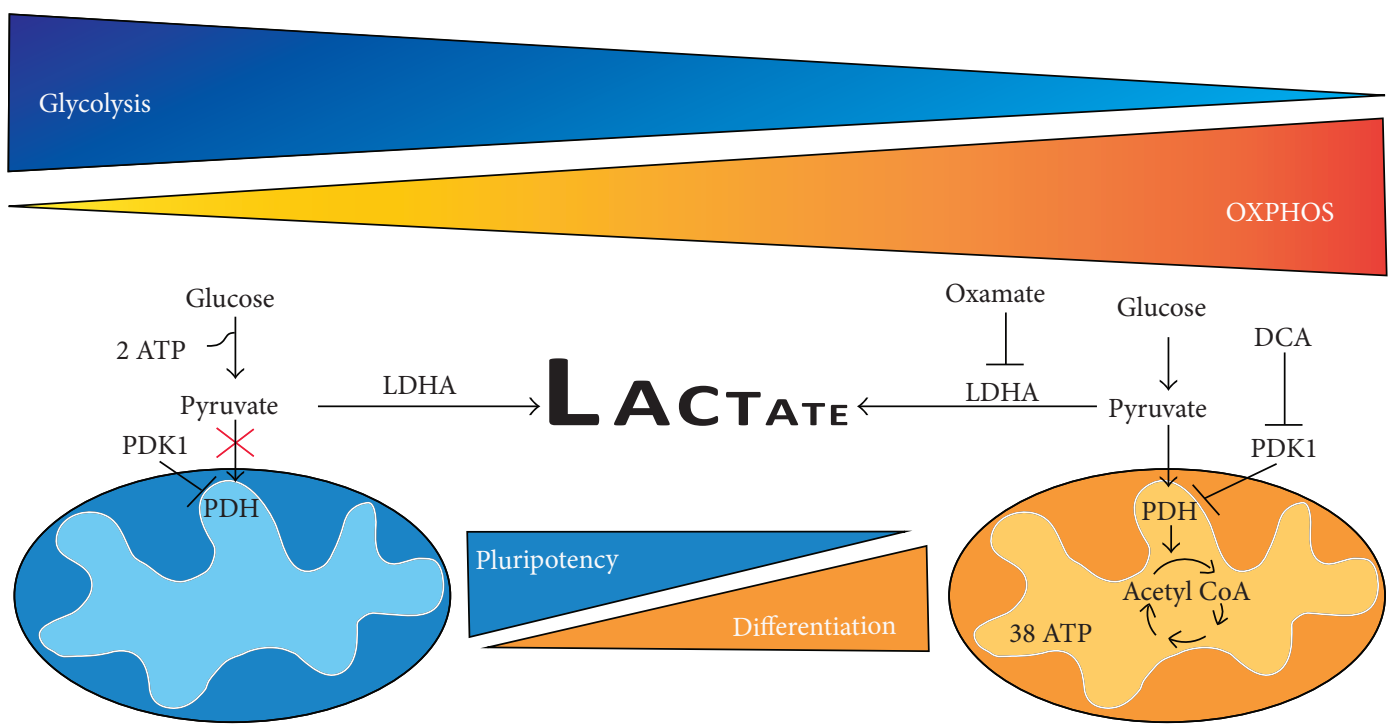

Figure 4: General overview of ECCs differentiation and the metabolic transition associated with the loss of stemness. ECCs can be differentiated towards neuronal and extraembryonic endoderm in the presence of retinoic acid, or cardiomyocytes in the presence of DMSO. With the differentiation process, others and we have observed a metabolic transition from glycolytic metabolism towards oxidative phosphorylation. Moreover, we can induce F9 cell differentiation towards an extraembryonic lineage using dichloroacetate (DCA), a pyruvate dehydrogenase kinase (PDK) inhibitor, or oxamate, a lactate dehydrogenase A (LDHA) inhibitor, which would indicate that the metabolic status of a cell determines whether it will remain pluripotent or if it will differentiate towards a specific lineage.

activation by fructose 2,6-bisphosphate, and thus increasing the glycolytic rate [318]. Similar results were reported in highly proliferative cells for lactate dehydrogenase A (LDHA), which converts pyruvate to lactate [319] and pyruvate dehydrogenase kinase (PDK), which by phosphorylating and blocking the pyruvate dehydrogenase (PDH) complex inhibits the conversion of pyruvate to acetyl Co-A in the mitochondria [320]. Undifferentiated P19 cells have a strong glycolytic profile, which is correlated with high levels of Oct4, Sox2, and Nanog [320]. Similarly, we have found that F9 cells maintained in the undifferentiated state have high levels of LDHA and PDK1 (manuscript in preparation) (Figure 4). This parallels the increased lactate and pyruvate production seen in differentiating P19 cells [321]. The fate of pyruvate in these cells, however, differs significantly between the undifferentiated and differentiated cells, as when cells are grown in the presence of galactose, pyruvate is shuttled to the mitochondria and this is associated with reduced stemness [320]. It is interesting to note that undifferentiated P19 cells have fewer mitochondrial proteins [322] compared to their differentiated counterparts, even though both have similar mitochondrial DNA copy number [320]. This may not be a general phenomenon for all ECCs, as we have seen the opposite in F9 cells (manuscript in preparation). Similar mitochondrial DNA copy number between the undifferentiated and differentiated state is likely offset by mitochondrial activity, highly prevalent in differentiated ECCs, and substrate availability, which would fuel these mitochondria. What is perplexing is that P19 cells induced to form cardiomyocytes initially have low mitochondrial DNA content and ATP levels during the early stages of differentiation, but both eventually return to basal levels [323]. That these changes are not expected to occur during differentiation only reinforces the idea of the complex, nonuniversal nature and specificity of cellular metabolism in maintaining stemness or promoting differentiation. We have shown that F9 cells differentiate when OXPHOS metabolism is promoted (Figure 4), and this parallels what was reported earlier for P19 cells [320]. Likewise, while many have shown that the differentiation of ECCs is accompanied by a shift in the metabolic profile towards OXPHOS [320-322], it remains to be determined if this metabolic transition precedes the differentiation process 
or is the result of it. If we are to champion one or the other, it would probably be the former given the evidence that mouse embryonic fibroblasts reprogrammed using the Yamanaka factors transition to glycolytic metabolism prior to the induction of pluripotency [324]. This phenomenon, if general, would indicate that metabolism might be the master regulator of pluripotency and stemness and not just their slave in preventing differentiation.

\section{Conclusion}

Using ECCs as our platform we have highlighted some of the dramatic interplay that must exist between key genes and their regulators for these cells to remain pluripotent and to self-renew. Extrapolating many of these events to ESCs and CSCs in vivo has been fruitful in many cases, but as we have noted on several occasions, there are fundamental differences that preclude striking a unifying model. Other means of regulation are known to play key roles in ECC self-renewal and differentiation, including modifications imparted by reactive oxygen species (ROS) [325, 326], as well as the influence of ROS homeostasis in cellular programming [300, 327], cell cycle control as demonstrated in ESCs [328-333], as well as long noncoding RNAs in these cells [334-337]. In fact, signaling through $\mathrm{Ca}^{2+}$ channels in ECCs has also been reported to be involved in regulation [338]. Changes to the epigenome and chromatin remodeling, however, have garnered much attention. Together, we expect that in the future a better understanding of how these changes contribute to selfrenewal and pluripotency in development will only serve to elucidate a major question on the minds of everyone-why do we get cancer?

\section{Competing Interests}

The authors declare that there is no conflict of interests regarding the publication of this paper.

\section{Acknowledgments}

Gregory M. Kelly would like to thank the Natural Sciences and Engineering Research Council of Canada for funding. The authors also acknowledge the Faculty of Graduate and Postgraduate Studies, Western University, for support to Mohamed I. Gatie. Gregory M. Kelly would like to dedicate his part of the review to Dr. Iskra Sarafov for her constant reminders that a single view through the telescope captures much more than several views through the microscope. Mohamed I. Gatie would like to dedicate his portion of the review to Nesrine Cheikh, and both authors would especially like to thank Tina Nicole Cuthbert for her feedback on this manuscript.

\section{References}

[1] K. Takahashi and S. Yamanaka, "Induction of pluripotent stem cells from mouse embryonic and adult fibroblast cultures by defined factors," Cell, vol. 126, no. 4, pp. 663-676, 2006.
[2] M. Stadtfeld and K. Hochedlinger, "Induced pluripotency: history, mechanisms, and applications," Genes \& Development, vol. 24, no. 20, pp. 2239-2263, 2010.

[3] S. Yamanaka, "Induced pluripotent stem cells: past, present, and future," Cell Stem Cell, vol. 10, no. 6, pp. 678-684, 2012.

[4] I. Damjanov, "Teratocarcinoma: neoplastic lessons about normal embryogenesis," International Journal of Developmental Biology, vol. 37, no. 1, pp. 39-46, 1993.

[5] P. W. Andrews, "Teratocarcinomas and human embryology: pluripotent human EC cell lines. Review article," APMIS, vol. 106, no. 1-6, pp. 158-168, 1998.

[6] L. C. Stevens, "The biology of teratomas," Advances in Morphogenesis, vol. 6, pp. 1-31, 1967.

[7] G. B. Pierce, "Teratocarcinoma: model for a developmental concept of cancer," Current Topics in Developmental Biology, vol. 2, pp. 223-246, 1967.

[8] P. W. Andrews, "From teratocarcinomas to embryonic stem cells," Philosophical Transactions of the Royal Society B: Biological Sciences, vol. 357, no. 1420, pp. 405-417, 2002.

[9] I. Chambers and A. Smith, "Self-renewal of teratocarcinoma and embryonic stem cells," Oncogene, vol. 23, no. 43, pp. 71507160, 2004.

[10] J. Rossant and V. E. Papaioannou, “The relationship between embryonic, embryonal carcinoma and embryo-derived stem cells," Cell Differentiation, vol. 15, no. 2-4, pp. 155-161, 1984.

[11] J. E. Wheeler, "History of teratomas," in The Human Teratomas: Experimental and Clinical Biology, I. Damjanov, B. B. Knowles, and D. Solter, Eds., pp. 1-22, Humana Press, Totowa, NJ, USA, 1983.

[12] H. Gavriel and S. Kleid, "Benign neck metastasis of a testicular germ cell tumor," International Surgery, vol. 100, no. 1, pp. 164$168,2015$.

[13] J. J. Cunningham, T. M. Ulbright, M. F. Pera, and L. H. J. Looijenga, "Lessons from human teratomas to guide development of safe stem cell therapies," Nature Biotechnology, vol. 30, no. 9, pp. 849-857, 2012.

[14] T. Newsom-Davis, D. Poulter, R. Gray et al., "Case report: malignant teratoma of the uterine corpus," BMC Cancer, vol. 9, article 195, 2009.

[15] I. Damjanov, B. B. Knowles, and D. Solter, The human teratomas: experimental and clinical biology, vol. 3, Humana Press, 1983.

[16] E. Pantoja, M. A. Noy, R. W. Axtmayer, F. E. Colon, and I. Pelegrina, "Ovarian dermoids and their complications comprehensive historical review," Obstetrical and Gynecological Survey, vol. 30, no. 1, pp. 1-20, 1975.

[17] D. Solter, N. Škreb, and I. Damjanov, "Extrauterine growth of mouse egg-cylinders results in malignant teratoma," Nature, vol. 227, no. 5257, pp. 503-504, 1970.

[18] L. C. Stevens, "Origin of testicular teratomas from primordial germ cells in mice," Journal of the National Cancer Institute, vol. 38, no. 4, pp. 549-552, 1967.

[19] D. G. Lanza, E. P. Dawson, P. Rao, and J. D. Heaney, "Misexpression of cyclin D1 in embryonic germ cells promotes testicular teratoma initiation," Cell Cycle, vol. 15, no. 7, pp. 919-930, 2016.

[20] X. Bustamante-Marín, J. A. Garness, and B. Capel, “Testicular teratomas: an intersection of pluripotency, differentiation and cancer biology," The International Journal of Developmental Biology, vol. 57, no. 2-4, pp. 201-210, 2013.

[21] F. Jacob, "Mouse teratocarcinoma and embryonic antigens," IMMUNOL.REV., vol. 33, pp. 3-32, 1977. 
[22] J. Rossant and V. E. Papaioannou, "Outgrowth of embryonal carcinoma cells from injected blastocysts in vitro correlates with abnormal chimera development in vivo," Experimental Cell Research, vol. 156, no. 1, pp. 213-220, 1985.

[23] L. J. Kleinsmith and G. B. Pierce Jr., "Multipotentiality of single embryonal carcinoma cells," Cancer Research, vol. 24, no. 9, pp. 1544-1551, 1964.

[24] B. W. Finch and B. Ephrussi, "Retention of multiple developmental potentialities by cells of a mouse testicular teratocarcinoma during prolonged culture in vitro and their extinction upon hybridization with cells of permanent lines," Proceedings of the National Academy of Sciences, vol. 57, no. 3, pp. 615-621, 1967.

[25] R. L. Brinster, "The effect of cells transferred into the mouse blastocyst on subsequent development," Journal of Experimental Medicine, vol. 140, no. 4, pp. 1049-1056, 1974.

[26] V. E. Papaioannou, M. W. Mcburney, R. L. Gardner, and M. J. Evans, "Fate of teratocarcinoma cells injected into early mouse embryos," Nature, vol. 258, no. 5530, pp. 70-73, 1975.

[27] R. H. Blelloch, K. Hochedlinger, Y. Yamada et al., "Nuclear cloning of embryonal carcinoma cells," Proceedings of the National Academy of Sciences of the United States of America, vol. 101, no. 39, pp. 13985-13990, 2004.

[28] J. F. Nicolas, P. Avner, J. Gaillard, J. L. Guenet, H. Jakob, and F. Jacob, "Cell lines derived from teratocarcinomas," Cancer Research, vol. 36, no. 11, pp. 4224-4231, 1976.

[29] B. Blum and N. Benvenisty, "The tumorigenicity of human embryonic stem cells," Advances in Cancer Research, vol. 100, pp. 133-158, 2008.

[30] D. Solter, "From teratocarcinomas to embryonic stem cells and beyond: a history of embryonic stem cell research," Nature Reviews Genetics, vol. 7, no. 4, pp. 319-327, 2006.

[31] T. Liu, Y. Wang, X. Peng et al., "Establishment of Mouse Teratocarcinomas Stem Cells Line and Screening Genes Responsible for Malignancy," PLoS ONE, vol. 7, no. 8, Article ID e43955, 2012.

[32] J. Kanungo, "Retinoic acid signaling in P19 stem cell differentiation," Anti-Cancer Agents in Medicinal Chemistry, vol. 16, 2016.

[33] G. R. Martin, “Teratocarcinomas and mammalian embryogenesis," Science, vol. 209, no. 4458, pp. 768-776, 1980.

[34] G. R. Martin, "Teratocarcinomas as a model system for the study of embryogenesis and neoplasia," Cell, vol. 5, no. 3, pp. 229-243, 1975.

[35] M. Evans, "Discovering pluripotency: 30 years of mouse embryonic stem cells," Nature Reviews Molecular Cell Biology, vol. 12, no. 10, pp. 680-686, 2011.

[36] E. G. Bernstine, M. L. Hooper, S. Grandchamp, and B. Ephrussi, "Alkaline phosphatase activity in mouse teratoma," Proceedings of the National Academy of Sciences, vol. 70, no. 12, pp. 38993903, 1973.

[37] A. Alonso, B. Breuer, B. Steuer, and J. Fischer, "The F9-EC cell line as a model for the analysis of differentiation," The International Journal of Developmental Biology, vol. 35, no. 4, pp. 389-397, 1991.

[38] B. Boer, C. T. Bernadt, M. Desler, P. J. Wilder, J. L. Kopp, and A. Rizzino, "Differential activity of the FGF-4 enhancer in F9 and P19 embryonal carcinoma cells," Journal of Cellular Physiology, vol. 208, no. 1, pp. 97-108, 2006.

[39] M. I. Sherman and R. A. Miller, "F9 embryonal carcinoma cells can differentiate into endoderm-like cells," Developmental Biology, vol. 63, no. 1, pp. 27-34, 1978.
[40] B. L. M. Hogan, A. Taylor, and E. Adamson, "Cell interactions modulate embryonal carcinoma cell differentiation into parietal or visceral endoderm," Nature, vol. 291, no. 5812, pp. 235-237, 1981.

[41] D. W. Han, N. Tapia, M. J. Araúzo-Bravo et al., "Sox2 level is a determinant of cellular reprogramming potential," PLoS ONE, vol. 8, no. 6, Article ID e67594, 2013.

[42] S. Strickland and V. Mahdavi, "The induction of differentiation in teratocarcinoma stem cells by retinoic acid," Cell, vol. 15, no. 2, pp. 393-403, 1978.

[43] E. Lehtonen, A. Laasonen, and J. Tienari, "Teratocarcinoma stem cells as a model for differentiation in the mouse embryo," International Journal of Developmental Biology, vol. 33, no. 1, pp. 105-115, 1989.

[44] M. W. McBurney and B. J. Rogers, "Isolation of male embryonal carcinoma cells and their chromosome replication patterns," Developmental Biology, vol. 89, no. 2, pp. 503-508, 1982.

[45] M. W. McBurney, "P19 embryonal carcinoma cells," The International Journal of Developmental Biology, vol. 37, no. 1, pp. 135140, 1993.

[46] G. Bain, W. J. Ray, M. Yao, and D. I. Gottlieb, "From embryonal carcinoma cells to neurons: the P19 pathway," BioEssays, vol. 16, no. 5, pp. 343-348, 1994.

[47] M. A. G. Van Der Heyden and L. H. K. Defize, "Twenty one years of P19 cells: what an embryonal carcinoma cell line taught us about cardiomyocyte differentiation," Cardiovascular Research, vol. 58, no. 2, pp. 292-302, 2003.

[48] M. K. S. Edwards and M. W. McBurney, "The concentration of retinoic acid determines the differentiated cell types formed by a teratocarcinoma cell line," Developmental Biology, vol. 98, no. 1, pp. 187-191, 1983.

[49] M. W. McBurney, E. M. V. Jones-Villeneuve, M. K. S. Edwards, and P. J. Anderson, "Control of muscle and neuronal differentiation in a cultured embryonal carcinoma cell line," Nature, vol. 299, no. 5879, pp. 165-167, 1982.

[50] C. Dony, M. Kessel, and P. Gruss, "An embryonal carcinoma cell line as a model system to study developmentally regulated genes during myogenesis," Cell Differentiation, vol. 15, no. 2-4, pp. 275-279, 1984.

[51] E. M. Jones-Villeneuve, "Retinoic acid induces embryonal carcinoma cells to differentiate into neurons and glial cells," The Journal of Cell Biology, vol. 94, no. 2, pp. 253-262, 1982.

[52] J. Kanungo, "Tumor suppressors and endodermal differentiation of P19 embryonic stem cells," Cell \& Developmental Biology, vol. 4, no. 3, article no. el38, 2015.

[53] G. T. Snoek, C. L. Mummery, C. E. van den Brink, P. T. van der Saag, and S. W. de Laat, "Protein kinase C and phorbol ester receptor expression related to growth and differentiation of nullipotent and pluripotent embryonal carcinoma cells," Developmental Biology, vol. 115, no. 2, pp. 282-292, 1986.

[54] C. A. Boulter and E. F. Wagner, "Expression of c-src and cabl in embryonal carcinoma cells and adult mouse tissues," Experimental Cell Research, vol. 179, no. 1, pp. 214-221, 1988.

[55] S. K. Mallanna, B. Boer, M. Desler, and A. Rizzino, "Differential regulation of the Oct-3/4 gene in cell culture model systems that parallel different stages of mammalian development," Molecular Reproduction and Development, vol. 75, no. 8, pp. 1247-1257, 2008.

[56] P. W. Andrews, I. Damjanov, D. Simon et al., "Pluripotent embryonal carcinoma clones derived from the human teratocarcinoma cell line Tera-2. Differentiation in vivo and in vitro," Laboratory Investigation, vol. 50, no. 2, pp. 147-162, 1984. 
[57] P. W. Andrews, "Human teratocarcinomas," Biochimica et Biophysica Acta (BBA)-Reviews on Cancer, vol. 948, no. 1, pp. 1736, 1988.

[58] M. V. Wiles, "Isolation of differentially expressed human cDNA clones: similarities between mouse and human embryonal carcinoma cell differentiation," Development, vol. 104, no. 3, pp. 403-413, 1988.

[59] C. L. Mummery, M. A. van Rooijen, S. E. van den Brink, and S. W. de Laat, "Cell cycle analysis during retinoic acid induced differentiation of a human embryonal carcinoma-derived cell line," Cell Differentiation, vol. 20, no. 2-3, pp. 153-160, 1987.

[60] P. W. Andrews, "Retinoic acid induces neuronal differentiation of a cloned human embryonal carcinoma cell line in vitro," Developmental Biology, vol. 103, no. 2, pp. 285-293, 1984.

[61] P. W. Andrews, E. Gonczol, S. A. Plotkin, M. Dignazio, and J. W. Oosterhuis, "Differentiation of TERA-2 human embryonal carcinoma cells into neurons and HCMV permissive cells. Induction by agents other than retinoic acid," Differentiation, vol. 31, no. 2, pp. 119-126, 1986.

[62] S. J. Pleasure and V. M. -. Lee, "NTera 2 cells: a human cell line which displays characteristics expected of a human committed neuronal progenitor cell," Journal of Neuroscience Research, vol. 35, no. 6, pp. 585-602, 1993.

[63] R. Pal and G. Ravindran, "Assessment of pluripotency and multilineage differentiation potential of NTERA-2 cells as a model for studying human embryonic stem cells," Cell Proliferation, vol. 39, no. 6, pp. 585-598, 2006.

[64] W. M. W. Cheung, A. H. Chu, and N. Y. Ip, "Identification of candidate genes induced by retinoic acid in embryonal carcinoma cells," Journal of Neurochemistry, vol. 68, no. 5, pp. 1882-1888, 1997.

[65] M. J. Spinella, S. Kitareewan, B. Mellado, D. Sekula, K.-S. Khoo, and E. Dmitrovsky, "Specific retinoid receptors cooperate to signal growth suppression and maturation of human embryonal carcinoma cells," Oncogene, vol. 16, no. 26, pp. 3471-3480, 1998.

[66] R. J. Alfonso, I. Gorroño-Etxebarria, M. Rabano, M. M. Vivanco, and R. Kypta, "Dickkopf-3 alters the morphological response to retinoic acid during neuronal differentiation of human embryonal carcinoma cells," Developmental Neurobiology, vol. 74, no. 12, pp. 1243-1254, 2014.

[67] M. J. Spinella, S. J. Freemantle, D. Sekula, J. H. Chang, A. J. Christie, and E. Dmitrovsky, "Retinoic acid promotes ubiquitination and proteolysis of cyclin D1 during induced tumor cell differentiation," Journal of Biological Chemistry, vol. 274, no. 31, pp. 22013-22018, 1999.

[68] R. S. V. Chadalavada, J. E. Korkola, J. Houldsworth et al., "Constitutive gene expression predisposes morphogen-mediated cell fate responses of NT2/D1 and 27X-1 human embryonal carcinoma cells," Stem Cells, vol. 25, no. 3, pp. 771-778, 2007.

[69] M. F. Pera and D. Herszfeld, "Differentiation of human pluripotent teratocarcinoma stem cells induced by bone morphogenetic protein-2," Reproduction, Fertility and Development, vol. 10, no. 7-8, pp. 551-555, 1998.

[70] K. C. Davidson, E. A. Mason, and M. F. Pera, "The pluripotent state in mouse and human," Development, vol. 142, no. 18, pp. 3090-3099, 2015.

[71] G. Kelly and T. Drysdale, "Retinoic acid and the development of the endoderm," Journal of Developmental Biology, vol. 3, no. 2, pp. 25-56, 2015.

[72] L. J. Gudas and J. A. Wagner, "Retinoids regulate stem cell differentiation," Journal of Cellular Physiology, vol. 226, no. 2, pp. 322-330, 2011.
[73] D. R. Soprano, B. W. Teets, and K. J. Soprano, "Role of retinoic acid in the differentiation of embryonal carcinoma and embryonic stem cells," Vitamins and Hormones, vol. 75, pp. 69-95, 2007.

[74] K. Brown, S. Legros, J. Artus et al., "A comparative analysis of extra-embryonic endoderm cell lines," PLoS ONE, vol. 5, no. 8, 2010.

[75] C. Eifert, N. Sangster-Guity, L.-M. Yu et al., "Global gene expression profiles associated with retinoic acid-induced differentiation of embryonal carcinoma cells," Molecular Reproduction and Development, vol. 73, no. 7, pp. 796-824, 2006.

[76] M. A. Mendoza-Parra, M. Walia, M. Sankar, and H. Gronemeyer, "Dissecting the retinoid-induced differentiation of F9 embryonal stem cells by integrative genomics," Molecular Systems Biology, vol. 7, no. 1, article no. 538, 2011.

[77] E. Moutier, T. Ye, M. Choukrallah et al., "Retinoic acid receptors recognize the mouse genome through binding elements with diverse spacing and topology," Journal of Biological Chemistry, vol. 287, no. 31, pp. 26328-26341, 2012.

[78] A. Chatagnon, P. Veber, V. Morin et al., "RAR/RXR binding dynamics distinguish pluripotency from differentiation associated cis-regulatory elements," Nucleic Acids Research, vol. 43, no. 10, pp. 4833-4854, 2015.

[79] T. Harris and G. Childs, "Global gene expression patterns during differentiation of F9 embryonal carcinoma cells into parietal endoderm," Functional \& Integrative Genomics, vol. 2, no. 3, pp. 105-119, 2002.

[80] S. Lalevee, Y. N. Anno, A. Chatagnon et al., "Genome-wide in silico identification of new conserved and functional retinoic acid receptor response elements (direct repeats separated by 5 bp)," Journal of Biological Chemistry, vol. 286, no. 38, pp. 3332233334, 2011.

[81] Y. Wei, T. Harris, and G. Childs, "Global gene expression patterns during neural differentiation of P19 embryonic carcinoma cells," Differentiation, vol. 70, no. 4-5, pp. 204-219, 2002.

[82] F. Leypoldt, J. Lewerenz, and A. Methner, "Identification of genes up-regulated by retinoic-acid-induced differentiation of the human neuronal precursor cell line NTERA-2 cl.D1," Journal of Neurochemistry, vol. 76, no. 3, pp. 806-814, 2001.

[83] R. St-Arnaud, A. Nepveu, K. B. Marcu, and M. W. McBurney, "Two transient increases in c-myc gene expression during neuroectodermal differentiation of mouse embryonal carcinoma cells," Oncogene, vol. 3, no. 5, pp. 553-559, 1988.

[84] K. D. Nakamura and R. W. Hart, "Proto-oncogene expression during retinoic acid-induced neural differentiation of embryonal carcinoma cells," Mechanisms of Ageing and Development, vol. 48, no. 1, pp. 53-62, 1989.

[85] N. V. Varlakhanova, R. F. Cotterman, W. N. deVries et al., "Myc maintains embryonic stem cell pluripotency and self-renewal," Differentiation, vol. 80, no. 1, pp. 9-19, 2010.

[86] A. Vlad, S. Röhrs, L. Klein-Hitpass, and O. Müller, "The first five years of the Wnt targetome," Cellular Signalling, vol. 20, no. 5, pp. 795-802, 2008.

[87] E. Schuuring, L. Van Deemter, H. Roelink, and R. Nusse, "Transient expression of the proto-oncogene int-1 during differentiation of P19 embryonal carcinoma cells," Molecular and Cellular Biology, vol. 9, no. 3, pp. 1357-1361, 1989.

[88] R. St-Arnaud, J. Craig, M. W. McBurney, and J. Papkoff, "The int-1 proto-oncogene is transcriptionally activated during neuroectodermal differentiation of P19 mouse embryonal carcinoma cells," Oncogene, vol. 4, no. 9, pp. 1077-1080, 1989. 
[89] J. Papkoff, "Identification and biochemical characterization of secreted Wnt-1 protein from P19 embryonal carcinoma cells induced to differentiate along the neuroectodermal lineage," Oncogene, vol. 9, no. 1, pp. 313-317, 1994.

[90] B. D. Smolich, J. A. McMahon, A. P. McMahon, and J. Papkoff, "Wnt family proteins are secreted and associated with the cell surface," Molecular Biology of the Cell, vol. 4, no. 12, pp. 12671275, 1993.

[91] B. D. Smolich and J. Papkoff, "Regulated expression of Wnt family members during neuroectodermal differentiation of P19 embryonal carcinoma cells: overexpression of Wnt-1 perturbs normal differentiation-specific properties," Developmental Biology, vol. 166, no. 1, pp. 300-310, 1994.

[92] K. Tang, J. Yang, X. Gao et al., "Wnt-1 promotes neuronal differentiation and inhibits gliogenesis in P19 cells," Biochemical and Biophysical Research Communications, vol. 293, no. 1, pp. 167-173, 2002.

[93] R. Krawetz and G. M. Kelly, "Wnt6 induces the specification and epithelialization of F9 embryonal carcinoma cells to primitive endoderm," Cellular Signalling, vol. 20, no. 3, pp. 506-517, 2008.

[94] G. Golenia, M. I. Gatie, and G. M. Kelly, "Frizzled gene expression and negative regulation of canonical WNT- $\beta$-catenin signaling in mouse F9 teratocarcinoma cells," Biochemistry and Cell Biology, 2016.

[95] J. A. Wakeman, J. Walsh, and P. W. Andrews, "Human Wnt13 is developmentally regulated during the differentiation of NTERA-2 pluripotent human embryonal carcinoma cells," Oncogene, vol. 17, no. 2, pp. 179-186, 1998.

[96] C. Elizalde, V. M. Campa, M. Caro et al., "Distinct roles for Wnt-4 and Wnt-11 during retinoic acid-induced neuronal differentiation," Stem Cells, vol. 29, no. 1, pp. 141-153, 2011.

[97] A. Rizzino and E. L. Wuebben, "Sox2/Oct4: a delicately balanced partnership in pluripotent stem cells and embryogenesis," Biochimica et Biophysica Acta-Gene Regulatory Mechanisms, vol. 1859, no. 6, pp. 780-791, 2016.

[98] A. Rizzino, "Concise review: the Sox2-Oct4 connection: critical players in a much larger interdependent network integrated at multiple levels," Stem Cells, vol. 31, no. 6, pp. 1033-1039, 2013.

[99] V. Kashyap, N. C. Rezende, K. B. Scotland et al., "Regulation of Stem cell pluripotency and differentiation involves a mutual regulatory circuit of the Nanog, OCT4, and SOX2 pluripotency transcription factors with polycomb repressive complexes and stem cell microRNAs," Stem Cells and Development, vol. 18, no. 7, pp. 1093-1108, 2009.

[100] I. Chambers and S. R. Tomlinson, "The transcriptional foundation of pluripotency," Development, vol. 136, no. 14, pp. 23112322, 2009.

[101] C. Y. Leung and M. Zernicka-Goetz, "Mapping the journey from totipotency to lineage specification in the mouse embryo," Current Opinion in Genetics and Development, vol. 34, pp. 71-76, 2015.

[102] H. Ng and M. A. Surani, "The transcriptional and signalling networks of pluripotency," Nature Cell Biology, vol. 13, no. 5, pp. 490-496, 2011.

[103] P. Miang-Lon Ng and T. Lufkin, "Embryonic stem cells: protein interaction networks," BioMolecular Concepts, vol. 2, no. 1-2, pp. 13-25, 2011.

[104] J. Campisi, H. E. Gray, A. B. Pardee, M. Dean, and G. E. Sonenshein, "Cell-cycle control of c-myc but not c-ras expression is lost following chemical transformation," Cell, vol. 36, no. 2, pp. 241-247, 1984.
[105] K. Nishikura, U. Kim, and J. M. Murray, "Differentiation of F9 cells is independent of c-myc expression," Oncogene, vol. 5, no. 7, pp. 981-988, 1990.

[106] T. J. Lockett and M. J. Sleigh, "Oncogene expression in differentiating F9 mouse embryonal carcinoma cells," Experimental Cell Research, vol. 173, no. 2, pp. 370-378, 1987.

[107] M. J. Sleigh, "Differential regulation of viral and cellular genes in F9 mouse embyronal carcinoma cells," Nucleic Acids Research, vol. 15, no. 22, pp. 9379-9395, 1987.

[108] J. Schoorlemmer, L. Jonk, S. Shen, A. van Puijenbroek, A. Feijen, and W. Kruijer, "Regulation of Oct-4 gene expression during differentiation of EC cells," Molecular Biology Reports, vol. 21, no. 3, pp. 129-140, 1995.

[109] H. R. Scholer, R. Balling, A. K. Hatzopoulos, N. Suzuki, and P. Gruss, "Octamer binding proteins confer transcriptional activity in early mouse embryogenesis," EMBO Journal, vol. 8, no. 9, pp. 2551-2557, 1989.

[110] V. Botquin, H. Hess, G. Fuhrmann et al., "New POU dimer configuration mediates antagonistic control of an osteopontin preimplantation enhancer by Oct- 4 and Sox-2," Genes and Development, vol. 12, no. 13, pp. 2073-2090, 1998.

[111] H. Yuan, N. Corbi, C. Basilico, and L. Dailey, "Developmentalspecific activity of the FGF-4 enhancer requires the synergistic action of Sox 2 and Oct-3," Genes and Development, vol. 9, no. 21, pp. 2635-2645, 1995.

[112] L. R. Johnson, K. A. Lamb, Q. Gao, T. K. Nowling, and A. Rizzino, "Role of the transcription factor Sox-2 in the expression of the FGF-4 gene in embryonal carcinoma cells," Molecular Reproduction and Development, vol. 50, no. 4, pp. 377-386, 1998.

[113] M. S. Wiebe, P. J. Wilder, D. Kelly, and A. Rizzino, "Isolation, characterization, and differential expression of the murine Sox2 promoter," Gene, vol. 246, no. 1-2, pp. 383-393, 2000.

[114] J. J. Schuringa, S. Van der Schaaf, E. Vellenga, B. J. L. Eggen, and W. Kruijer, "LIF-induced STAT3 signaling in murine versus human embryonal carcinoma (EC) cells," Experimental Cell Research, vol. 274, no. 1, pp. 119-129, 2002.

[115] A. Velcich, P. Delli-Bovi, A. Mansukhani, E. B. Ziff, and C. Basilico, "Expression of the $\mathrm{K}$-fgf protooncogene is repressed during differentiation of F9 cells," Oncogene Research, vol. 5, no. 1, pp. 31-37, 1989.

[116] T. Yoshida, H. Muramatsu, T. Muramatsu et al., "Differential expression of two homologous and clustered oncogenes, Hstl and Int-2, during differentiation of F9 cells," Biochemical and Biophysical Research Communications, vol. 157, no. 2, pp. 618625, 1988.

[117] J. Tiesman and A. Rizzino, "Expression and developmental regulation of the $\mathrm{k}-\mathrm{FGF}$ oncogene in human and murine embryonal carcinoma cells," In Vitro Cellular \& Developmental Biology, vol. 25, no. 12, pp. 1193-1198, 1989.

[118] M.-Y. Lee, A. Lu, and L. J. Gudas, “Transcriptional regulation of Rexl (zfp42) in normal prostate epithelial cells and prostate cancer cells," Journal of Cellular Physiology, vol. 224, no. 1, pp. 17-27, 2010.

[119] E. Dmitrovsky, D. Moy, W. H. Miller Jr., A. Li, and H. Masui, "Retinoic acid causes a decline in TGF- $\alpha$ expression, cloning efficiency, and tumorigenicity in a human embryonal cancer cell line," Oncogene Research, vol. 5, no. 3, pp. 233-239, 1990.

[120] W. H. Miller Jr., D. Moy, A. Li, J. F. Grippo, and E. Dmitrovsky, "Retinoic acid induces down-regulation of several growth factors and proto-oncogenes in a human embryonal cancer cell line," Oncogene, vol. 5, no. 4, pp. 511-517, 1990. 
[121] T. Pierce, H. J. Worman, and J. Holy, "Neuronal differentiation of NT2/D1 teratocarcinoma cells is accompanied by a loss of lamin A/C expression and an increase in lamin B1 expression," Experimental Neurology, vol. 157, no. 2, pp. 241-250, 1999.

[122] W. Shi, H. Wang, G. Pan, Y. Geng, Y. Guo, and D. Pei, "Regulation of the pluripotency marker Rex-1 by Nanog and Sox2," Journal of Biological Chemistry, vol. 281, no. 33, pp. 2331923325, 2006.

[123] B. A. Hosler, G. J. LaRosa, J. F. Grippo, and L. J. Gudas, "Expression of REX-1, a gene containing zinc finger motifs, is rapidly reduced by retinoic acid in F9 teratocarcinoma cells," Molecular and Cellular Biology, vol. 9, no. 12, pp. 5623-5629, 1989.

[124] S. Kawazoe, N. Ikeda, K. Miki et al., "Extrinsic factors derived from mouse embryonal carcinoma cell lines maintain pluripotency of mouse embryonic stem cells through a novel signal pathway," Development Growth and Differentiation, vol. 51, no. 2, pp. 81-93, 2009.

[125] S.-C. Choi, J.-H. Choi, C.-Y. Park, C.-M. Ahn, S.-J. Hong, and D.-S. Lim, "Nanog regulates molecules involved in stemness and cell cycle-signaling pathway for maintenance of pluripotency of P19 embryonal carcinoma stem cells," Journal of Cellular Physiology, vol. 227, no. 11, pp. 3678-3692, 2012.

[126] T. Sejersen, J. Sümegi, and N. R. Ringertz, "Expression of cellular oncogenes in teratoma-derived cell lines," Experimental Cell Research, vol. 160, no. 1, pp. 19-30, 1985.

[127] M. M. Whitman, Y.-M. Shen, K. J. Soprano, and D. Soprano, "Molecular analysis of early growth-associated events during the differentiation of F9 cells into embryoid bodies," Cancer Research, vol. 50, no. 11, pp. 3193-3198, 1990.

[128] R. Finklestein and R. A. Weinberg, "Differential regulation of N-myc and c-myc expression in F9 teratocarcinoma cells," Oncogene Research, vol. 3, no. 3, pp. 287-292, 1988.

[129] A. Nepveu, R. A. Levine, J. Campisi, M. E. Greenberg, E. B. Ziff, and K. B. Marcu, "Alternative modes of c-myc regulation in growth factor-stimulated and differentiating cells," Oncogene, vol. 1, no. 3, pp. 243-250, 1987.

[130] A. E. Griep and H. F. DeLuca, "Decreased c-myc expression is an early event in retinoic acid-induced differentiation of F9 teratocarcinoma cells," Proceedings of the National Academy of Sciences, vol. 83, no. 15, pp. 5539-5543, 1986.

[131] K. Okamoto, H. Okazawa, A. Okuda, M. Sakai, M. Muramatsu, and H. Hamada, "A novel octamer binding transcription factor is differentially expressed in mouse embryonic cells," Cell, vol. 60, no. 3, pp. 461-472, 1990.

[132] H. R. Scholer, A. K. Hatzopoulos, R. Balling, N. Suzuki, and P. Gruss, "A family of octamer-specific proteins present during mouse embryogenesis: evidence for germline-specific expression of an Oct factor," EMBO Journal, vol. 8, no. 9, pp. 2543-2550, 1989.

[133] L. Wang and G. A. Schultz, "Expression of Oct-4 during differentiation of murine F9 cells," Biochemistry and Cell Biology, vol. 74, no. 4, pp. 579-584, 1996.

[134] B. Boer, J. L. Cox, D. Claassen, S. K. Mallanna, M. Desler, and A. Rizzino, "Regulation of the Nanog gene by both positive and negative cis-regulatory elements in embryonal carcinoma cells and embryonic stem cells," Molecular Reproduction and Development, vol. 76, no. 2, pp. 173-182, 2009.

[135] Y. Chen, Z. Du, and Z. Yao, "Roles of the Nanog protein in murine F9 embryonal carcinoma cells and their endodermdifferentiated counterparts," Cell Research, vol.16, no. 7, pp. 641650, 2006.
[136] Z. Xie, G. Tan, M. Ding et al., "Foxm1 transcription factor is required for maintenance of pluripotency of P19 embryonal carcinoma cells," Nucleic Acids Research, vol. 38, no. 22, pp. 8027-8038, 2010.

[137] A. Gong and S. Huang, "FoxM1 and Wnt/ $\beta$-catenin signaling in glioma stem cells," Cancer Research, vol. 72 , no. 22, pp. 5658$5662,2012$.

[138] I. Wierstra, "The transcription factor FOXM1 (Forkhead box M1): proliferation-specific expression, transcription factor function, target genes, mouse models, and normal biological roles," Advances in Cancer Research, vol. 118, pp. 97-398, 2013.

[139] S. A. Kakhki, M. Shahhoseini, and G. H. Salekdeh, "Comparative SRY incorporation on the regulatory regions of pluripotency/differentiation genes in human embryonic carcinoma cells after retinoic acid induction," Molecular and Cellular Biochemistry, vol. 376, no. 1-2, pp. 145-150, 2013.

[140] A. E. Griep and H. Westphal, "Antisense Myc sequences induce differentiation of F9 cells," Proceedings of the National Academy of Sciences, vol. 85, no. 18, pp. 6806-6810, 1988.

[141] Z. Qin, F. Ren, X. Xu et al., "ZNF536, a novel zinc finger protein specifically expressed in the brain, negatively regulates neuron differentiation by repressing retinoic acid-induced gene transcription," Molecular and Cellular Biology, vol. 29, no. 13, pp. 3633-3643, 2009.

[142] C. L. Mummery, H. Slager, W. Kruijer et al., "Expression of transforming growth factor $\beta_{2}$ during the differentiation of murine embryonal carcinoma and embryonic stem cells," Developmental Biology, vol. 137, no. 1, pp. 161-170, 1990.

[143] A. G. Smith and M. L. Hooper, "Buffalo rat liver cells produce a diffusible activity which inhibits the differentiation of murine embryonal carcinoma and embryonic stem cells," Developmental Biology, vol. 121, no. 1, pp. 1-9, 1987.

[144] S. C. Pruitt and T. A. Natoli, "Inhibition of differentiation by leukemia inhibitory factor distinguishes two induction pathways in P19 embryonal carcinoma cells," Differentiation, vol. 50, no. 1, pp. 57-65, 1992.

[145] G. M. Hocke, "The LIF-response element confers LIF-induced transcriptional control in P19 embryonal carcinoma cells," Annals of the New York Academy of Sciences, vol. 762, pp. 426428, 1995.

[146] G. M. Hocke, M.-Z. Cui, and G. H. Fey, "The LIF response element of the $\alpha_{2}$ macroglobulin gene confers LIF-induced transcriptional activation in embryonal stem cells," Cytokine, vol. 7, no. 6, pp. 491-502, 1995.

[147] G. R. Martin, "Isolation of a pluripotent cell line from early mouse embryos cultured in medium conditioned by teratocarcinoma stem cells," Proceedings of the National Academy of Sciences, vol. 78, no. 12, pp. 7634-7638, 1981.

[148] N. A. Nicola and J. J. Babon, "Leukemia inhibitory factor (LIF)," Cytokine \& Growth Factor Reviews, vol. 26, no. 5, pp. 533-544, 2015.

[149] A. A. F. L. Van Puijenbroek, P. T. Van Der Saag, and P. J. Coffer, "Cytokine signal transduction in P19 embryonal carcinoma cells: regulation of Stat3-mediated transactivation occurs independently of p21ras-Erk signaling," Experimental Cell Research, vol. 251, no. 2, pp. 465-476, 1999.

[150] S. K. Gupta, A. J. Haggarty, S. Carbonetto, R. J. Riopelle, P. M. Richardson, and R. J. Dunn, "Trophic actions of ciliary neurotrophic factor on murine embryonic carcinoma cells," European Journal of Neuroscience, vol. 5, no. 8, pp. 977-985, 1993. 
[151] J. Pacherník, V. Horváth, L. Kubala, P. Dvořák, A. Kozubík, and A. Hampl, "Neural differentiation potentiated by the leukaemia inhibitory factor through STAT3 signalling in mouse embryonal carcinoma cells," Folia Biologica, vol. 53, no. 5, pp. 157-163, 2007.

[152] G. S. Brown, M. A. Brown, D. Hilton, N. M. Gough, and M. J. Sleigh, "Inhibition of differentiation in a murine f9 embryonal carcinoma cell subline by leukemia inhibitory factor (LIF)," Growth Factors, vol. 7, no. 1, pp. 41-52, 1992.

[153] K. Hirayoshi, A. Tsuru, M. Yamashita et al., "Both D factor/LIF and IL-6 inhibit the differentation of mouse teratocarcinoma F9 cells," FEBS Letters, vol. 282, no. 2, pp. 401-404, 1991.

[154] A. Inoue, A. Nagafuchi, and A. Kikuchi, "Retinoic acid induces discrete Wnt-signaling-dependent differentiation in F9 cells," Biochemical and Biophysical Research Communications, vol. 390, no. 3, pp. 564-569, 2009.

[155] S. Yin, H. Wu, J. Lv et al., "SHP-1 arrests mouse early embryo development through downregulation of Nanog by dephosphorylation of STAT3," PLoS ONE, vol. 9, no. 1, Article ID e86330, 2014.

[156] D. Y. Wu and Z. Yao, "Isolation and characterization of the murine Nanog gene promoter," Cell Research, vol. 15, no. 5, pp. 317-324, 2005.

[157] T. Kuroda, M. Tada, H. Kubota et al., "Octamer and sox elements are required for transcriptional cis regulation of Nanog gene expression," Molecular and Cellular Biology, vol. 25, no. 6, pp. 2475-2485, 2005.

[158] G. Pan, J. Li, Y. Zhou, H. Zheng, and D. Pei, "A negative feedback loop of transcription factors that controls stem cell pluripotency and self-renewal," The FASEB Journal, vol. 20, no. 10, pp. 17301732, 2006.

[159] B. Boer, J. Kopp, S. Mallanna et al., "Elevating the levels of Sox 2 in embryonal carcinoma cells and embryonic stem cells inhibits the expression of Sox2:Oct-3/4 target genes," Nucleic Acids Research, vol. 35, no. 6, pp. 1773-1786, 2007.

[160] M. Pesce and H. R. Schöler, "Oct-4: gatekeeper in the beginnings of mammalian development," Stem Cells, vol. 19, no. 4, pp. 271-278, 2001.

[161] H. Li, R. Fan, M. Sun, T. Jiang, and Y. Gong, "Nspcl regulates the key pluripotent Oct4-Nanog-Sox2 axis in P19 embryonal carcinoma cells via directly activating Oct4," Biochemical and Biophysical Research Communications, vol. 440, no. 4, pp. 527532, 2013.

[162] J. Schoorlemmer, A. Van Puijenbroek, M. Van Den Eijnden, L. Jonk, C. Pals, and W. Kruijer, "Characterization of a negative retinoic acid response element in the murine Oct4 promoter," Molecular and Cellular Biology, vol. 14, no. 2, pp. 1122-1136, 1994.

[163] E. Pikarsky, H. Sharir, E. Ben-Shushan, and Y. Bergman, "Retinoic acid represses Oct-3/4 gene expression through several retinoic acid-responsive elements located in the promoterenhancer region," Molecular and Cellular Biology, vol. 14, no. 2, pp. 1026-1038, 1994.

[164] E. Ben-Shushan, H. Sharir, E. Pikarsky, and Y. Bergman, "A dynamic balance between ARP-1/COUP-TFII, EAR-3/COUPTFI, and retinoic acid receptor:retinoid $\mathrm{X}$ receptor heterodimers regulates Oct-3/4 expression in embryonal carcinoma cells," Molecular and Cellular Biology, vol. 15, no. 2, pp. 1034-1048, 1995.

[165] S. Minucci, V. Botquin, Y. I. Yeom et al., "Retinoic acid-mediated down-regulation of Oct $3 / 4$ coincides with the loss of promoter occupancy in vivo," EMBO Journal, vol. 15, no. 4, pp. 888-899, 1996.
[166] E. Ben-Shushan, J. R. Thompson, L. J. Gudas, and Y. Bergman, "Rex-1, a gene encoding a transcription factor expressed in the early embryo, is regulated via Oct-3/4 and Oct- 6 binding to an octamer site and a novel protein, Rox-1, binding to an adjacent site," Molecular and Cellular Biology, vol. 18, no. 4, pp. 18661878, 1998.

[167] E. Rosfjord and A. Rizzino, "The octamer motif present in the Rex-1 promoter binds Oct-1 and Oct-3 expressed by EC cells and ES cells," Biochemical and Biophysical Research Communications, vol. 203, no. 3, pp. 1795-1802, 1994.

[168] Y. Marikawa, D. A. A. Tamashiro, T. C. Fujita, and V. B. Alarcon, "Dual roles of Oct 4 in the maintenance of mouse P19 embryonal carcinoma cells: as negative regulator of Wnt/ $\beta$-catenin signaling and competence provider for brachyury induction," Stem Cells and Development, vol. 20, no. 4, pp. 621-633, 2011.

[169] G. Lin, L. Zhao, F. Yin et al., "TCF3 inhibits F9 embryonal carcinoma growth by the down-regulation of Oct4," Oncology Reports, vol. 26, no. 4, pp. 893-899, 2011.

[170] J. Lyu, F. Costantini, E.-H. Jho, and C.-K. Joo, "Ectopic expression of axin blocks neuronal differentiation of embryonic carcinoma P19 cells," Journal of Biological Chemistry, vol. 278, no. 15, pp. 13487-13495, 2003.

[171] H. Liu, S. Deng, Z. Zhao et al., "Oct4 regulates the miR-302 cluster in P19 mouse embryonic carcinoma cells," Molecular Biology Reports, vol. 38, no. 3, pp. 2155-2160, 2011.

[172] H. Hohjoh and T. Fukushima, "Marked change in microRNA expression during neuronal differentiation of human teratocarcinoma NTera2D1 and mouse embryonal carcinoma P19 cells," Biochemical and Biophysical Research Communications, vol. 362, no. 2, pp. 360-367, 2007.

[173] B. Huang, W. Li, B. Zhao et al., "MicroRNA expression profiling during neural differentiation of mouse embryonic carcinoma P19 cells," Acta Biochimica et Biophysica Sinica, vol. 41, no. 3, pp. 231-236, 2009.

[174] C. Bräutigam, A. Raggioli, and J. Winter, “The Wnt/ $\beta$-catenin pathway regulates the expression of the miR-302 cluster in mouse ESCs and P19 cells," PLoS ONE, vol. 8, no. 9, Article ID e75315, 2013.

[175] S. Zhang, Y. Li, Y. Wu, K. Shi, L. Bing, and J. Hao, "Wnt $/ \beta$-Catenin signaling pathway upregulates c-Myc expression to promote cell proliferation of P19 teratocarcinoma cells," Anatomical Record, vol. 295, no. 12, pp. 2104-2113, 2012.

[176] S. F. Vencken, P. Sethupathy, G. Blackshields et al., "An integrated analysis of the SOX2 microRNA response program in human pluripotent and nullipotent stem cell lines," $B M C$ Genomics, vol. 15, article 711, 2014.

[177] W. H. Neo, K. Yap, S. H. Lee et al., "MicroRNA miR-124 controls the choice between neuronal and astrocyte differentiation by fine-tuning Ezh2 expression," The Journal of Biological Chemistry, vol. 289, no. 30, pp. 20788-20801, 2014.

[178] H. Hohjoh, "MicroRNA expression during neuronal differentiation of human teratocarcinoma NTera2D1 and mouse embryonic carcinoma P19 cells," in MicroRNA Protocols, vol. 936 of Methods in Molecular Biology, pp. 257-269, Springer, 2013.

[179] B. Zhao, B. Huang, W. Li, and Y. Jin, "MicroRNA expression profiling during neural differentiation of mouse embryonic carcinoma P19 cells," Methods in Molecular Biology, vol. 936, pp. 105-116, 2013.

[180] L. F. Sempere, S. Freemantle, I. Pitha-Rowe, E. Moss, E. Dmitrovsky, and V. Ambros, "Expression profiling of mammalian 
microRNAs uncovers a subset of brain-expressed microRNAs with possible roles in murine and human neuronal differentiation," Genome Biology, vol. 5, no. 3, article R13, 2004.

[181] U. Lakshmipathy, B. Love, L. A. Goff et al., "MicroRNA expression pattern of undifferentiated and differentiated human embryonic stem cells," Stem Cells and Development, vol. 16, no. 6, pp. 1003-1016, 2007.

[182] A. Eda, Y. Tamura, M. Yoshida, and H. Hohjoh, "Systematic gene regulation involving miRNAs during neuronal differentiation of mouse P19 embryonic carcinoma cell," Biochemical and Biophysical Research Communications, vol. 388, no. 4, pp. 648653, 2009.

[183] B. D. Manning and L. C. Cantley, "AKT/PKB signaling: navigating downstream," Cell, vol. 129, no. 7, pp. 1261-1274, 2007.

[184] J. Bastien, J.-L. Plassat, B. Payrastre, and C. Rochette-Egly, "The phosphoinositide 3-kinase/Akt pathway is essential for the retinoic acid-induced differentiation of F9 cells," Oncogene, vol. 25, no. 14, pp. 2040-2047, 2006.

[185] J. H. Lee, S. Y. Shin, S. Kim, J. Choo, and Y. H. Lee, "Suppression of PTEN expression during aggregation with retinoic acid in P19 mouse embryonal carcinoma cells," Biochemical and Biophysical Research Communications, vol. 347, no. 3, pp. 715-722, 2006.

[186] B. Chen, Z. Xue, G. Yang et al., "Akt-signal integration is involved in the differentiation of embryonal carcinoma cells," PLOS ONE, vol. 8, no. 6, Article ID e64877, 2013.

[187] J. S. Kim, B. S. Kim, J. Kim, C. S. Park, and I. Y. Chung, "The phosphoinositide-3-kinase/Akt pathway mediates the transient increase in Nanog expression during differentiation of F9 cells," Archives of Pharmacal Research, vol. 33, no. 7, pp. 1117-1125, 2010.

[188] Y. Lin, Y. Yang, W. Li et al., "Reciprocal regulation of Akt and Oct4 promotes the self-renewal and survival of embryonal carcinoma cells," Molecular Cell, vol. 48, no. 4, pp. 627-640, 2012.

[189] D. S. Griffiths, J. Li, M. A. Dawson et al., "LIF-independent JAK signalling to chromatin in embryonic stem cells uncovered from an adult stem cell disease," Nature Cell Biology, vol. 13, no. 1, pp. 13-21, 2011.

[190] D. C. Di Giammartino and E. Apostolou, "The chromatin signature of pluripotency: establishment and maintenance," Current Stem Cell Reports, vol. 2, no. 3, pp. 255-262, 2016.

[191] L. Fagnocchi, S. Mazzoleni, and A. Zippo, "Integration of signaling pathways with the epigenetic machinery in the maintenance of stem cells," Stem Cells International, vol. 2016, Article ID 8652748, 13 pages, 2016.

[192] C. Marcho, W. Cui, and J. Mager, "Epigenetic dynamics during preimplantation development," Reproduction, vol. 150, no. 3, pp. R109-R120, 2015.

[193] M. Perino and G. Veenstra, "Chromatin control of developmental dynamics and plasticity," Developmental Cell, vol. 38, no. 6, pp. 610-620, 2016.

[194] M. A. Surani, K. Hayashi, and P. Hajkova, "Genetic and epigenetic regulators of pluripotency," Cell, vol. 128, no. 4, pp. 747762, 2007.

[195] R. Fraser and C. Lin, "Epigenetic reprogramming of the zygote in mice and men: on your marks, get set, go!", Reproduction, vol. 152, no. 6, pp. R211-R222, 2016.

[196] Z. D. Smith, C. Sindhu, and A. Meissner, "Molecular features of cellular reprogramming and development," Nature Reviews Molecular Cell Biology, vol. 17, no. 3, pp. 139-154, 2016.

[197] A. T. Clark, "DNA methylation remodeling in vitro and in vivo," Current Opinion in Genetics \& Development, vol. 34, pp. 82-87, 2015.
[198] M. J. Boland, K. L. Nazor, and J. F. Loring, "Epigenetic regulation of pluripotency and differentiation," Circulation Research, vol. 115, no. 2, pp. 311-324, 2014.

[199] W. Tee and D. Reinberg, "Chromatin features and the epigenetic regulation of pluripotency states in ESCs," Development, vol. 141, no. 12, pp. 2376-2390, 2014.

[200] R. C. Adam and E. Fuchs, "The Yin and Yang of chromatin dynamics in stem cell fate selection," Trends in Genetics, vol. 32, no. 2, pp. 89-100, 2016.

[201] R. Hersmus, Y. van Bever, K. P. Wolffenbuttel, K. Biermann, M. Cools, and L. H. Looijenga, "The biology of germ cell tumors in disorders of sex development," Clinical Genetics, vol. 91, no. 2, pp. 292-301, 2017.

[202] L. Cheng, M.-T. Sung, P. Cossu-Rocca et al., "OCT4: biological functions and clinical applications as a marker of germ cell neoplasia," Journal of Pathology, vol. 211, no. 1, pp. 1-9, 2007.

[203] R. Eini, L. C. Dorssers, and L. H. Looijenga, "Role of stem cell proteins and microRNAs in embryogenesis and germ cell cancer," The International Journal of Developmental Biology, vol. 57, no. 2-3-4, pp. 319-332, 2013.

[204] S. Conrad, H. Azizi, M. Hatami et al., "Expression of genes related to germ cell lineage and pluripotency in single cells and colonies of human adult germ stem cells," Stem Cells International, vol. 2016, Article ID 8582526, 17 pages, 2016.

[205] I. Virant-Klun, A. Ståhlberg, M. Kubista, and T. Skutella, "MicroRNAs: from female fertility, germ cells, and stem cells to cancer in humans," Stem Cells International, vol. 2016, Article ID 3984937, 17 pages, 2016.

[206] M. A. Rijlaarsdam, D. M. Tax, A. J. Gillis et al., "Genome wide DNA methylation profiles provide clues to the origin and pathogenesis of germ cell tumors," PLoS ONE, vol. 10, no. 4, Article ID e0122146, 2015.

[207] R. Eini, H. Stoop, A. J. M. Gillis, K. Biermann, L. C. J. Dorssers, and L. H. J. Looijenga, "Role of SOX2 in the etiology of embryonal carcinoma, based on analysis of the NCCIT and NT2 cell lines," PLoS ONE, vol. 9, no. 1, Article ID e83585, 2014.

[208] Y. G. Van Der Zwan, H. Stoop, F. Rossello, S. J. White, and L. $\mathrm{H}$. Looijenga, "Role of epigenetics in the etiology of germ cell cancer," The International Journal of Developmental Biology, vol. 57, no. 2-3-4, pp. 299-308, 2013.

[209] G. Kaati, L. O. Bygren, and S. Edvinsson, "Cardiovascular and diabetes mortality determined by nutrition during parents' and grandparents' slow growth period," European Journal of Human Genetics, vol. 10, no. 11, pp. 682-688, 2002.

[210] C. Sun, D. P. Burgner, A.-L. Ponsonby et al., "Effects of earlylife environment and epigenetics on cardiovascular disease risk in children: highlighting the role of twin studies," Pediatric Research, vol. 73, no. 4, part 2, pp. 523-530, 2013.

[211] P. Quintero-Ronderos and G. Montoya-Ortiz, "Epigenetics and autoimmune diseases," Autoimmune Diseases, vol. 2012, Article ID 593720, 16 pages, 2012.

[212] R. Stöger, "Epigenetics and obesity," Pharmacogenomics, vol. 9, no. 12, pp. 1851-1860, 2008.

[213] G. Egger, G. Liang, A. Aparicio, and P. A. Jones, "Epigenetics in human disease and prospects for epigenetic therapy," Nature, vol. 429, no. 6990, pp. 457-463, 2004.

[214] M. Berdasco and M. Esteller, "Genetic syndromes caused by mutations in epigenetic genes," Human Genetics, vol. 132, no. 4, pp. 359-383, 2013.

[215] A. P. Feinberg and B. Vogelstein, "Hypomethylation distinguishes genes of some human cancers from their normal counterparts," Nature, vol. 301, no. 5895, pp. 89-92, 1983. 
[216] H. Wu and Y. Zhang, "Reversing DNA methylation: mechanisms, genomics, and biological functions," Cell, vol. 156, no. 1-2, pp. 45-68, 2014.

[217] Z. D. Smith and A. Meissner, "DNA methylation: roles in mammalian development," Nature Reviews Genetics, vol. 14, no. 3, pp. 204-220, 2013.

[218] J. Du, L. M. Johnson, S. E. Jacobsen, and D. J. Patel, "DNA methylation pathways and their crosstalk with histone methylation," Nature Reviews Molecular Cell Biology, vol. 16, no. 9, pp. 519-532, 2015.

[219] S. C. Hodawadekar and R. Marmorstein, "Chemistry of acetyl transfer by histone modifying enzymes: structure, mechanism and implications for effector design," Oncogene, vol. 26, no. 37, pp. 5528-5540, 2007.

[220] J. A. Law and S. E. Jacobsen, "Establishing, maintaining and modifying DNA methylation patterns in plants and animals," Nature Reviews Genetics, vol. 11, no. 3, pp. 204-220, 2010.

[221] H. Sasaki and Y. Matsui, "Epigenetic events in mammalian germ-cell development: reprogramming and beyond," Nature Reviews Genetics, vol. 9, no. 2, pp. 129-140, 2008.

[222] H. Wu and Y. Zhang, "Tetl and 5-hydroxymethylation: a genome-wide view in mouse embryonic stem cells," Cell Cycle, vol. 10, no. 15, pp. 2428-2436, 2011.

[223] R. L. Zhang, J. X. Meng, C. X. Liu et al., "Genome-wide screen of promoter methylation analysis of ES cells and ES derived epidermal-like cells," Cell Biochemistry and Function, vol. 33, no. 6, pp. 398-406, 2015.

[224] F. von Meyenn, M. Iurlaro, E. Habibi et al., "Impairment of DNA methylation maintenance is the main cause of global demethylation in naive embryonic stem cells," Molecular Cell, vol. 62 , no. 6 , pp. 848-861, 2016.

[225] K. Shirane, K. Kurimoto, Y. Yabuta et al., "Global landscape and regulatory principles of DNA methylation reprogramming for germ cell specification by mouse pluripotent stem cells," Developmental Cell, vol. 39, no. 1, pp. 87-103, 2016.

[226] C. J. Petell, L. Alabdi, M. He, P. San Miguel, R. Rose, and H. Gowher, "An epigenetic switch regulates de novo DNA methylation at a subset of pluripotency gene enhancers during embryonic stem cell differentiation," Nucleic Acids Research, vol. 44, no. 16, pp. 7605-7617, 2016.

[227] M. T. Pedersen, S. M. Kooistra, A. Radzisheuskaya et al., "Continual removal of H3K9 promoter methylation by Jmjd2 demethylases is vital for ESC self-renewal and early development," EMBO Journal, vol. 35, no. 14, pp. 1550-1564, 2016.

[228] Y. Ozkul and U. Galderisi, "The impact of epigenetics on mesenchymal stem cell biology," Journal of Cellular Physiology, vol. 231, no. 11, pp. 2393-2401, 2016.

[229] L. Morey, A. Santanach, and L. Di Croce, "Pluripotency and epigenetic factors in mouse embryonic stem cell fate regulation," Molecular and Cellular Biology, vol. 35, no. 16, pp. 2716-2728, 2015.

[230] Y. C. Lim, S. Y. Chia, S. Jin, W. Han, C. Ding, and L. Sun, "Dynamic DNA methylation landscape defines brown and white cell specificity during adipogenesis," Molecular Metabolism, vol. 5, no. 10, pp. 1033-1041, 2016.

[231] S. Jasty and S. Krishnakumar, "Profiling of DNA and histone methylation reveals epigenetic-based regulation of gene expression during retinal differentiation of stem/progenitor cells isolated from the ciliary pigment epithelium of human cadaveric eyes," Brain Research, vol. 1651, pp. 1-10, 2016.
[232] E. Hysolli, Y. Tanaka, J. Su et al., "Regulation of the DNA methylation landscape in human somatic cell reprogramming by the miR-29 family," Stem Cell Reports, vol. 7, no. 1, pp. 43-54, 2016.

[233] C. Gifford, M. Ziller, H. Gu et al., “Transcriptional and epigenetic dynamics during specification of human embryonic stem cells," Cell, vol. 153, no. 5, pp. 1149-1163, 2013.

[234] Y. Tamai, Y. Takemoto, M. Matsumoto, T. Morita, A. Matsushiro, and M. Nozaki, "Sequence of the EndoA gene encoding mouse cytokeratin and its methylation state in the CpG-rich region," Gene, vol. 104, no. 2, pp. 169-176, 1991.

[235] C. Cremisi, "Effect of 5-azacytidine treatment on mouse embryonal carcinoma cells," Journal of Cellular Physiology, vol. 116, no. 2, pp. 181-190, 1983.

[236] P. R. Young and S. M. Tilghman, "Induction of alpha-fetoprotein synthesis in differentiating F9 teratocarcinoma cells is accompanied by a genome-wide loss of DNA methylation," Molecular and Cellular Biology, vol. 4, no. 5, pp. 898-907, 1984.

[237] P. D. Burbelo, S. Horikoshi, and Y. Yamada, "DNA methylation and collagen IV gene expression in F9 teratocarcinoma cells," Journal of Biological Chemistry, vol. 265, no. 9, pp. 4839-4843, 1990.

[238] B. Teubner and W. A. Schulz, "Exemption of satellite DNA from demethylation in immortalized differentiated derivatives of F9 mouse embryonal carcinoma cells," Experimental Cell Research, vol. 210, no. 2, pp. 192-200, 1994.

[239] B. Teubner and W. A. Schulz, "Regulation of DNA methyltransferase during differentiation of F9 mouse embryonal carcinoma cells," Journal of Cellular Physiology, vol. 165, no. 2, pp. 284-290, 1995.

[240] T. H. Bestor, S. B. Hellewell, and V. M. Ingram, "Differentiation of two mouse cell lines is associated with hypomethylation of their genomes," Molecular and Cellular Biology, vol. 4, no. 9, pp. 1800-1806, 1984.

[241] A. Razin, C. Webb, M. Szyf et al., "Variations in DNA methylation during mouse cell differentiation in vivo and in vitro," Proceedings of the National Academy of Sciences, vol. 81, no. 8, pp. 2275-2279, 1984.

[242] A. Benazzouz and P. Duprey, “The vimentin promoter as a tool to analyze the early events of retinoic acid-induced differentiation of cultured embryonal carcinoma cells," Differentiation, vol. 65 , no. 3, pp. 171-180, 1999.

[243] R. Okano, T. Mita, and T. Matsui, "Characterization of a novel promoter structure and its transcriptional regulation of the murine laminin B1 gene," Biochimica et Biophysica Acta, vol. 1132, no. 1, pp. 49-57, 1992.

[244] P. K. Chiang, P. D. Burbelo, S. A. Brugh, R. K. Gordon, K. Fukuda, and Y. Yamada, "Activation of collagen IV gene expression in F9 teratocarcinoma cells by 3-deazaadenosine analogs. Indirect inhibitors of methylation," Journal of Biological Chemistry, vol. 267, no. 7, pp. 4988-4991, 1992.

[245] R. G. Oshima, K. Trevor, L. H. Shevinsky, O. A. Ryder, and G. Ceceña, "Identification of the gene coding for the Endo B murine cytokeratin and its methylated, stable inactive state in mouse nonepithelial cells," Genes \& Development, vol. 2, no. 5, pp. 505-516, 1988.

[246] P. Niforas, M. D. Chu, and P. Bird, "A retinoic acid/cAMPresponsive enhancer containing a cAMP responsive element is required for the activation of the mouse thrombomodulinencoding gene in differentiating F9 cells," Gene, vol. 176, no. 1-2, pp. 139-147, 1996. 
[247] I. Hatada, S. Morita, M. Kimura, T. Horii, R. Yamashita, and K. Nakai, "Genome-wide demethylation during neural differentiation of P19 embryonal carcinoma cells," Journal of Human Genetics, vol. 53, no. 2, pp. 185-191, 2008.

[248] A. Yeivin, A. Levine, and A. Razin, "DNA methylation patterns in tumors derived from F9 cells resemble methylation at the blastula stage," FEBS Letters, vol. 395, no. 1, pp. 11-16, 1996.

[249] L. Frostesjö, I. Holm, B. Grahn, A. W. Page, T. H. Bestor, and O. Heby, "Interference with DNA methyltransferase activity and genome methylation during F9 teratocarcinoma stem cell differentiation induced by polyamine depletion," Journal of Biological Chemistry, vol. 272, no. 7, pp. 4359-4366, 1997.

[250] A. Slack, N. Cervoni, M. Pinard, and M. Szyf, "Feedback regulation of DNA methyltransferase gene expression by methylation," European Journal of Biochemistry, vol. 264, no. 1, pp. 191199, 1999.

[251] R. P. De Groot, F. A. E. Kruyt, P. T. Van Der Saag, and W. Kruijer, "Ectopic expression of c-jun leads to differentiation of P19 embryonal carcinoma cells," The EMBO Journal, vol. 9, no. 6, pp. 1831-1837, 1990.

[252] D. Abbey and P. B. Seshagiri, "Aza-induced cardiomyocyte differentiation of P19 EC-cells by epigenetic co-regulation and ERK signaling," Gene, vol. 526, no. 2, pp. 364-373, 2013.

[253] P. Deb-Rinker, D. Ly, A. Jezierski, M. Sikorska, and P. R. Walker, "Sequential DNA methylation of the Nanog and Oct4 upstream regions in human NT2 cells during neuronal differentiation," Journal of Biological Chemistry, vol. 280, no. 8, pp. 6257-6260, 2005.

[254] P. Cartwright, C. McLean, A. Sheppard, D. Rivett, K. Jones, and S. Dalton, "LIF/STAT3 controls ES cell self-renewal and pluripotency by a Myc-dependent mechanism," Development, vol. 132, no. 5, pp. 885-896, 2005.

[255] Y. Marikawa, T. C. Fujita, and V. B. Alarcón, "Heterogeneous DNA methylation status of the regulatory element of the mouse Oct4 gene in adult somatic cell population," Cloning and Stem Cells, vol. 7, no. 1, pp. 8-16, 2005.

[256] H. S. Huang, T. M. Redmond, G. M. Kubish et al., "Transcriptional regulatory events initiated by Ascll and Neurog2 during neuronal differentiation of P19 embryonic carcinoma cells," Journal of Molecular Neuroscience, vol. 55, no. 3, pp. 684705, 2015.

[257] N. P. Mongan and L. J. Gudas, "Diverse actions of retinoid receptors in cancer prevention and treatment," Differentiation, vol. 75, no. 9, pp. 853-870, 2007.

[258] L.-N. Wei and C.-H. Lee, "Demethylation in the 5 '-flanking region of mouse cellular retinoic acid binding protein-I gene is associated with its high level of expression in mouse embryos and facilitates its induction by retinoic acid in P19 embryonal carcinoma cells," Developmental Dynamics, vol. 201, no. 1, pp. 1-10, 1994.

[259] Y. C. Choi and C. B. Chae, "Demethylation of somatic and testis-specific histone $\mathrm{H} 2 \mathrm{~A}$ and $\mathrm{H} 2 \mathrm{~B}$ genes in $\mathrm{F} 9$ embryonal carcinoma cells," Molecular and Cellular Biology, vol. 13, no. 9, pp. 5538-5548, 1993.

[260] Y. C. Choi, W. Gu, N. B. Hecht, A. P. Feinberg, and C. B. Chae, "Molecular cloning of mouse somatic and testis-specific $\mathrm{H} 2 \mathrm{~B}$ histone genes containing a methylated CpG island," DNA and Cell Biology, vol. 15, no. 6, pp. 495-504, 1996.

[261] J. Silke, K. I. Rother, O. Georgiev, W. Schaffner, and K. Matsuo, "Complex demethylation patterns at Spl binding sites in F9 embryonal carcinoma cells," FEBS Letters, vol. 370, no. 3, pp. 170-174, 1995.
[262] K. Tanaka, E. Appella, and G. Jay, "Developmental activation of the $\mathrm{H}-2 \mathrm{~K}$ gene is correlated with an increase in DNA methylation," Cell, vol. 35, no. 2, pp. 457-465, 1983.

[263] G. A. Bentley, A. Lewit-Bentley, J. T. Finch, A. D. Podjarny, and M. Roth, "Crystal structure of the nucleosome core particle at 16 Å resolution," Journal of Molecular Biology, vol. 176, no. 1, pp. 55-75, 1984.

[264] K. Luger, A. W. Mäder, R. K. Richmond, D. F. Sargent, and T. J. Richmond, "Crystal structure of the nucleosome core particle at 2.8 Å resolution,” Nature, vol. 389, no. 6648, pp. 251-260, 1997.

[265] V. G. Allfrey, R. Faulkner, and A. E. Mirsky, "Acetylation and methylation of histones and their possible role in the regulation of RNA synthesis," Proceedings of the National Academy of Sciences of the United States of America, vol. 51, no. 5, pp. 786794, 1964.

[266] M. Oki, H. Aihara, and T. Ito, "Role of histone phosphorylation in chromatin dynamics and its implications in diseases," SubCellular Biochemistry, vol. 41, pp. 319-336, 2007.

[267] S. S. Ng, W. W. Yue, U. Oppermann, and R. J. Klose, "Dynamic protein methylation in chromatin biology," Cellular and Molecular Life Sciences, vol. 66, no. 3, pp. 407-422, 2009.

[268] F. Lan and Y. Shi, "Epigenetic regulation: methylation of histone and non-histone proteins," Science in China Series C: Life Sciences, vol. 52, no. 4, pp. 311-322, 2009.

[269] H. Cedar and Y. Bergman, "Linking DNA methylation and histone modification: patterns and paradigms," Nature Reviews Genetics, vol. 10, no. 5, pp. 295-304, 2009.

[270] H. Fang, Y. Mi, Y. Zhang, N. Wu, and Y. Shen, "HDAC3 augments the autoregulation of neuroD gene in P19 cells," NeuroReport, vol. 21, no. 1, pp. 19-23, 2010.

[271] A. A. Serandour, S. Avner, F. Oger et al., "Dynamic hydroxymethylation of deoxyribonucleic acid marks differentiationassociated enhancers," Nucleic Acids Research, vol. 40, no. 17, pp. 8255-8265, 2012.

[272] M. Shahhoseini, A. Taei, N. Z. Mehrjardi, G. H. Salekdeh, and H. Baharvand, "Epigenetic analysis of human embryonic carcinoma cells during retinoic acid-induced neural differentiation," Biochemistry and Cell Biology, vol. 88, no. 3, pp. 527-538, 2010.

[273] N. Singhal, D. Esch, M. Stehling, and H. R. Schöler, "BRG1 is required to maintain pluripotency of murine embryonic stem cells," BioResearch Open Access, vol. 3, no. 1, pp. 1-8, 2014.

[274] Y. Chuang, W. Huang, S. W. Park et al., "Promyelocytic leukemia protein in retinoic acid-induced chromatin remodeling of Oct 4 gene promoter," STEM CELLS, vol. 29, no. 4, pp. 660-669, 2011.

[275] C. Wu, X. Feng, and L. Wei, "Coordinated repressive chromatinremodeling of Oct4 and Nanog genes in RA-induced differentiation of embryonic stem cells involves RIP140," Nucleic Acids Research, vol. 42, no. 7, pp. 4306-4317, 2014.

[276] C. T. Freberg, J. A. Dahl, S. Timoskainen, and P. Collas, "Epigenetic reprogramming of OCT4 and NANOG regulatory regions by embryonal carcinoma cell extract," Molecular Biology of the Cell, vol. 18, no. 5, pp. 1543-1553, 2007.

[277] D. W. Han, J. T. Do, M. J. Araúzo-Bravo et al., "Epigenetic hierarchy governing Nestin expression," Stem Cells, vol. 27, no. 5, pp. 1088-1097, 2009.

[278] K. B. Laursen, P. Wong, and L. J. Gudas, "Epigenetic regulation by RAR $\alpha$ maintains ligand-independent transcriptional activity," Nucleic Acids Research, vol. 40, no. 1, pp. 102-115, 2011.

[279] J. Pan, C. Jin, T. Murata, and K. K. Yokoyama, "Histone modification activities of JDP2 associated with retinoic acidinduced differentiation of F9 cells," Nucleic acids symposium series (2004), no. 48, pp. 189-190, 2004. 
[280] C. Jin, H. Li, T. Murata et al., "JDP2, a repressor of AP-1, recruits a histone deacetylase 3 complex to inhibit the retinoic acid-induced differentiation of F9 cells," Molecular and Cellular Biology, vol. 22, no. 13, pp. 4815-4826, 2002.

[281] C. Jin, H. Li, H. Ugai, T. Murata, and K. K. Yokoyama, "Transcriptional regulation of the c-jun gene by AP-1 repressor protein JDP2 during the differentiation of F9 cells," Nucleic Acids Research. Supplement, no. 2, pp. 97-98, 2002.

[282] G. Shi, F. Gao, and Y. Jin, "The regulatory role of histone deacetylase inhibitors in Fgf4 expression is dependent on the differentiation state of pluripotent stem cells," Journal of Cellular Physiology, vol. 226, no. 12, pp. 3190-3196, 2011.

[283] J. Liang, M. Wan, Y. Zhang et al., "Nanog and Oct4 associate with unique transcriptional repression complexes in embryonic stem cells," Nature Cell Biology, vol. 10, no. 6, pp. 731-739, 2008.

[284] G. A. Baltus, M. P. Kowalski, A. V. Tutter, and S. Kadam, "A positive regulatory role for the $\mathrm{mSin} 3 \mathrm{~A}-\mathrm{HDAC}$ complex in pluripotency through Nanog and Sox2," Journal of Biological Chemistry, vol. 284, no. 11, pp. 6998-7006, 2009.

[285] T. Chen, S. He, Z. Zhang, W. Gao, L. Yu, and Y. Tan, "Foxal contributes to the repression of Nanog expression by recruiting Grg3 during the differentiation of pluripotent P19 embryonal carcinoma cells," Experimental Cell Research, vol. 326, no. 2, pp. 326-335, 2014.

[286] T. Yamada, Y. Urano-Tashiro, S. Tanaka, H. Akiyama, F. Tashiro, and T. Akagi, "Involvement of crosstalk between Oct4 and Meisla in neural cell fate decision," PLoS ONE, vol. 8, no. 2, Article ID e56997, 2013.

[287] T. Chen and S. Y. Dent, "Chromatin modifiers and remodellers: regulators of cellular differentiation," Nature Reviews Genetics, vol. 15, no. 2, pp. 93-106, 2014.

[288] S. Orkin and K. Hochedlinger, "Chromatin connections to pluripotency and cellular reprogramming," Cell, vol. 145, no. 6, pp. 835-850, 2011.

[289] R. A. Levine, J. Campisi, S.-Y. Wang, and L. J. Gudas, "Butyrate inhibits the retinoic acid-induced differentiation of F9 teratocarcinoma stem cells," Developmental Biology, vol. 105, no. 2, pp. 443-450, 1984.

[290] M. Kosaka, Y. Nishina, M. Takeda, K. Matsumoto, and Y. Nishimune, "Reversible effects of sodium butyrate on the differentiation of F9 embryonal carcinoma cells," Experimental Cell Research, vol. 192, no. 1, pp. 46-51, 1991.

[291] S. Minucci, V. Horn, N. Bhattacharyya et al., "A histone deacetylase inhibitor potentiates retinoid receptor action in embryonal carcinoma cells," Proceedings of the National Academy of Sciences of the United States of America, vol. 94, no. 21, pp. 1129511300, 1997.

[292] B. Lefebvre, C. Brand, P. Lefebvre, and K. Ozato, "Chromosomal integration of retinoic acid response elements prevents cooperative transcriptional activation by retinoic acid receptor and retinoid X receptor," Molecular and Cellular Biology, vol. 22, no. 5, pp. 1446-1459, 2002.

[293] M. Moon, S. Um, and E. Kim, "CAC1 negatively regulates RAR $\alpha$ activity through cooperation with HDAC," Biochemical and Biophysical Research Communications, vol. 427, no. 1, pp. 41-46, 2012.

[294] A. Nebbioso, C. Dell'Aversana, A. Bugge et al., "HDACs class II-selective inhibition alters nuclear receptor-dependent differentiation," Journal of Molecular Endocrinology, vol. 45, no. 4, pp. 219-228, 2010.
[295] C. Johnson, M. O. Warmoes, X. Shen, and J. W. Locasale, "Epigenetics and cancer metabolism," Cancer Letters, vol. 356, no. 2, pp. 309-314, 2015.

[296] C. D. Folmes and A. Terzic, "Energy metabolism in the acquisition and maintenance of stemness," Seminars in Cell \& Developmental Biology, vol. 52, pp. 68-75, 2016.

[297] J. Wu, A. Ocampo, and J. C. Izpisua Belmonte, "Cellular metabolism and induced pluripotency," Cell, vol. 166, no. 6, pp. 1371-1385, 2016.

[298] T. Lonergan, C. Brenner, and B. Bavister, "Differentiationrelated changes in mitochondrial properties as indicators of stem cell competence," Journal of Cellular Physiology, vol. 208, no. 1, pp. 149-153, 2006.

[299] B. D. Bavister, "The mitochondrial contribution to stem cell biology," Reproduction, Fertility and Development, vol. 18, no. 8, pp. 829-838, 2006.

[300] P. Chaudhari, Z. Ye, and Y. Jang, "Roles of reactive oxygen species in the fate of stem cells," Antioxidants \& Redox Signaling, vol. 20, no. 12, pp. 1881-1890, 2014.

[301] J. Ramalho-Santos, S. Varum, S. Amaral, P. C. Mota, A. P. Sousa, and A. Amaral, "Mitochondrial functionality in reproduction: from gonads and gametes to embryos and embryonic stem cells," Human Reproduction Update, vol. 15, no. 5, pp. 553-572, 2009.

[302] J. Rehman, "Empowering self-renewal and differentiation: the role of mitochondria in stem cells," Journal of Molecular Medicine, vol. 88, no. 10, pp. 981-986, 2010.

[303] C. Chen, S. Hsu, and Y. Wei, "Mitochondrial bioenergetic function and metabolic plasticity in stem cell differentiation and cellular reprogramming," Biochimica et Biophysica Acta (BBA)-General Subjects, vol. 1820, no. 5, pp. 571-576, 2012.

[304] W. Zhou, M. Choi, D. Margineantu et al., "HIFl $\alpha$ induced switch from bivalent to exclusively glycolytic metabolism during ESCto-EpiSC/hESC transition," The EMBO Journal, vol. 31, no. 9, pp. 2103-2116, 2012.

[305] S. Varum, A. S. Rodrigues, M. B. Moura et al., "Energy metabolism in human pluripotent stem cells and their differentiated counterparts," PLoS ONE, vol. 6, no. 6, Article ID e20914, 2011.

[306] Y.-A. Shen, C.-Y. Wang, Y.-T. Hsieh, Y.-J. Chen, and Y.-H. Wei, "Metabolic reprogramming orchestrates cancer stem cell properties in nasopharyngeal carcinoma," Cell Cycle, vol. 14, no. 1, pp. 86-98, 2015.

[307] M. Peiris-Pagès, U. E. Martinez-Outschoorn, R. G. Pestell, F. Sotgia, and M. P. Lisanti, "Cancer stem cell metabolism," Breast Cancer Research, vol. 18, no. 1, article no. 55, 2016.

[308] R. A. Harris, L. Tindale, and R. C. Cumming, "Age-dependent metabolic dysregulation in cancer and Alzheimer's disease," Biogerontology, vol. 15, no. 6, pp. 559-577, 2014.

[309] R. A. Harris, L. Tindale, A. Lone et al., "Aerobic glycolysis in the frontal cortex correlates with memory performance in wild-type mice but not the APP/PS1 mouse model of cerebral amyloidosis," Journal of Neuroscience, vol. 36, no. 6, pp. 18711878, 2016.

[310] C. D. Folmes and A. Terzic, "Metabolic determinants of embryonic development and stem cell fate," Reproduction, Fertility and Development, vol. 27, no. 1, pp. 82-88, 2015.

[311] A. Prigione, M. V. Ruiz-Pérez, R. Bukowiecki, and J. Adjaye, "Metabolic restructuring and cell fate conversion," Cellular and Molecular Life Sciences, vol. 72, no. 9, pp. 1759-1777, 2015. 
[312] H. Jang, J. Yang, E. Lee, and J. Cheong, "Metabolism in embryonic and cancer stemness," Archives of Pharmacal Research, vol. 38, no. 3, pp. 381-388, 2015.

[313] A. Moussaieff, N. M. Kogan, and D. Aberdam, "Concise review: energy metabolites: key mediators of the epigenetic state of pluripotency," Stem Cells, vol. 33, no. 8, pp. 2374-2380, 2015.

[314] M. S. Kilberg, N. Terada, and J. Shan, "Influence of amino acid metabolism on embryonic stem cell function and differentiation," Advances in Nutrition, vol. 7, no. 4, pp. 780S-789S, 2016.

[315] O. Yanes, J. Clark, D. M. Wong et al., "Metabolic oxidation regulates embryonic stem cell differentiation," Nature Chemical Biology, vol. 6, no. 6, pp. 411-417, 2010.

[316] L. C. Shum, N. S. White, B. N. Mills, K. L. de Mesy Bentley, and R. A. Eliseev, "Energy metabolism in mesenchymal stem cells during osteogenic differentiation," Stem Cells and Development, vol. 25, no. 2, pp. 114-122, 2016.

[317] A. D. Panopoulos, O. Yanes, S. Ruiz et al., "The metabolome of induced pluripotent stem cells reveals metabolic changes occurring in somatic cell reprogramming," Cell Research, vol. 22, no. 1, pp. 168-177, 2011.

[318] H. E. Van Erp, G. Rijksen, P. T. Van Der Saag, and G. E. J. Staal, "Phosphofructokinase and pyruvate kinase in mouse embryonal carcinoma P19 cells in relation to growth and differentiation," Differentiation, vol. 45, no. 3, pp. 199-205, 1990.

[319] T. Kambe, J. Tada, M. Chikuma et al., "Embryonal carcinoma P19 cells produce erythropoietin constitutively but express lactate dehydrogenase in an oxygen-dependent manner," Blood, vol. 91, no. 4, pp. 1185-1195, 1998.

[320] I. Vega-Naredo, R. Loureiro, K. A. Mesquita et al., "Mitochondrial metabolism directs stemness and differentiation in P19 embryonal carcinoma stem cells," Cell Death and Differentiation, vol. 21, no. 10, pp. 1560-1574, 2014.

[321] S. Han, C. Auger, S. C. Thomas, C. L. Beites, and V. D. Appanna, "Mitochondrial biogenesis and energy production in differentiating murine stem cells: a functional metabolic study," Cellular Reprogramming, vol. 16, no. 1, pp. 84-90, 2014.

[322] J. Watkins, S. Basu, and D. F. Bogenhagen, "A quantitative proteomic analysis of mitochondrial participation in P19 cell neuronal differentiation," Journal of Proteome Research, vol. 7, no. 1, pp. 328-338, 2008.

[323] J. Jin, Q. Xuan, L. Zhou et al., "Dynamic mitochondrial changes during differentiation of P19 embryonic carcinoma cells into cardiomyocytes," Molecular Medicine Reports, vol. 10, no. 2, pp. 761-766, 2014.

[324] C. Folmes, T. Nelson, A. Martinez-Fernandez et al., "Somatic oxidative bioenergetics transitions into pluripotency-dependent glycolysis to facilitate nuclear reprogramming," Cell Metabolism, vol. 14, no. 2, pp. 264-271, 2011.

[325] R. Konopka, L. Kubala, A. Lojek, and J. Pacherník, "Alternation of retinoic acid induced neural differentiation of P19 embryonal carcinoma cells by reduction of reactive oxygen species intracellular production," Neuroendocrinology Letters, vol. 29, no. 5, pp. 770-774, 2008.

[326] L. Sandieson, J. T. K. Hwang, and G. M. Kelly, "Redox regulation of canonical Wnt signaling affects extraembryonic endoderm formation," Stem Cells and Development, vol. 23, no. 10, pp.10371049, 2014.

[327] S. Saito, Y. Lin, M. Tsai et al., "Emerging roles of hypoxia-inducible factors and reactive oxygen species in cancer and pluripotent stem cells," The Kaohsiung Journal of Medical Sciences, vol. 31, no. 6, pp. 279-286, 2015.
[328] B. Boward, T. Wu, and S. Dalton, "Concise review: control of cell fate through cell cycle and pluripotency networks," Stem Cells, vol. 34, no. 6, pp. 1427-1436, 2016.

[329] R. S. Wells, "An in vitro assay for growth regulation of embryonal carcinoma blastocyst," Cancer Research, vol. 42, no. 7, pp. 2736-2741, 1982.

[330] K. A. Lawson, J. J. Meneses, and R. A. Pedersen, "Clonal analysis of epiblast fate during germ layer formation in the mouse embryo," Development, vol. 113, no. 3, pp. 891-911, 1991.

[331] K. R. Boheler, "Stem cell pluripotency: a cellular trait that depends on transcription factors, chromatin state and a checkpoint deficient cell cycle," Journal of Cellular Physiology, vol. 221, no. 1, pp. 10-17, 2009.

[332] S. Dalton, "Linking the cell cycle to cell fate decisions," Trends in Cell Biology, vol. 25, no. 10, pp. 592-600, 2015.

[333] K. Kapinas, R. Grandy, P. Ghule et al., "The abbreviated pluripotent cell cycle," Journal of Cellular Physiology, vol. 228, no. 1, pp. 9-20, 2013.

[334] L. Chen and S. Zhang, "Long noncoding RNAs in cell differentiation and pluripotency," Cell and Tissue Research, vol. 366, no. 3, pp. 509-521, 2016.

[335] A. Rosa and M. Ballarino, "Long noncoding RNA regulation of pluripotency," Stem Cells International, vol. 2016, Article ID 1797692, 9 pages, 2016.

[336] Y. Li and Y. Wang, "Large noncoding RNAs are promising regulators in embryonic stem cells," Journal of Genetics and Genomics, vol. 42, no. 3, pp. 99-105, 2015.

[337] S. Ghosal, S. Das, and J. Chakrabarti, "Long noncoding RNAs: new players in the molecular mechanism for maintenance and differentiation of pluripotent stem cells," Stem Cells and Development, vol. 22, no. 16, pp. 2240-2253, 2013.

[338] R. R. Resende, J. L. Da Costa, A. H. Kihara, A. Adhikari, and E. Lorençon, "Intracellular $\mathrm{Ca}^{2+}$ regulation during neuronal differentiation of murine embryonal Carcinoma and Mesenchymal stem cells," Stem Cells and Development, vol. 19, no. 3, pp. 379-393, 2010. 

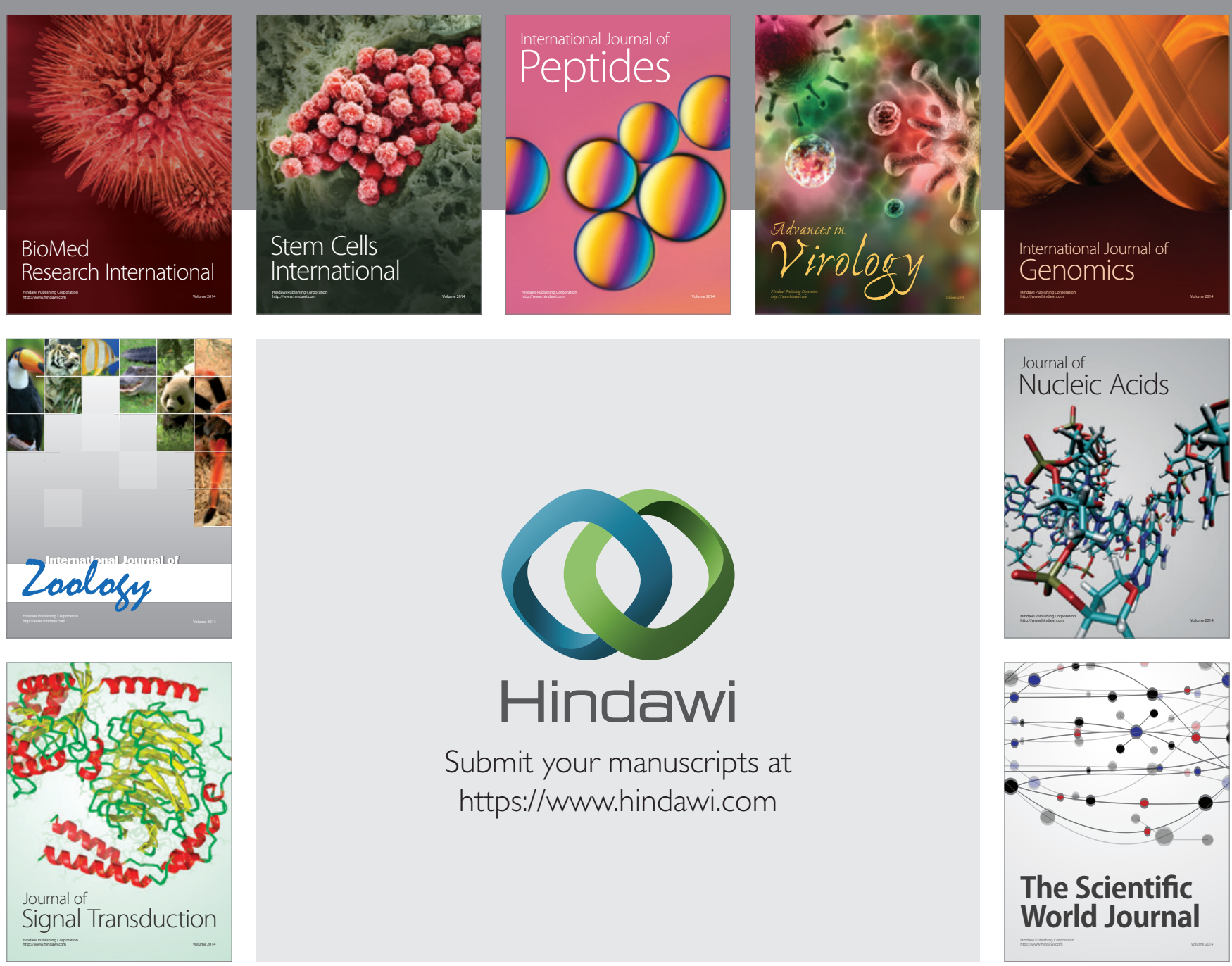

Submit your manuscripts at

https://www.hindawi.com
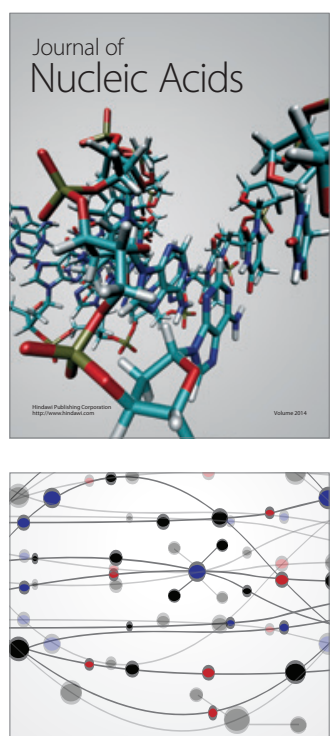

The Scientific World Journal
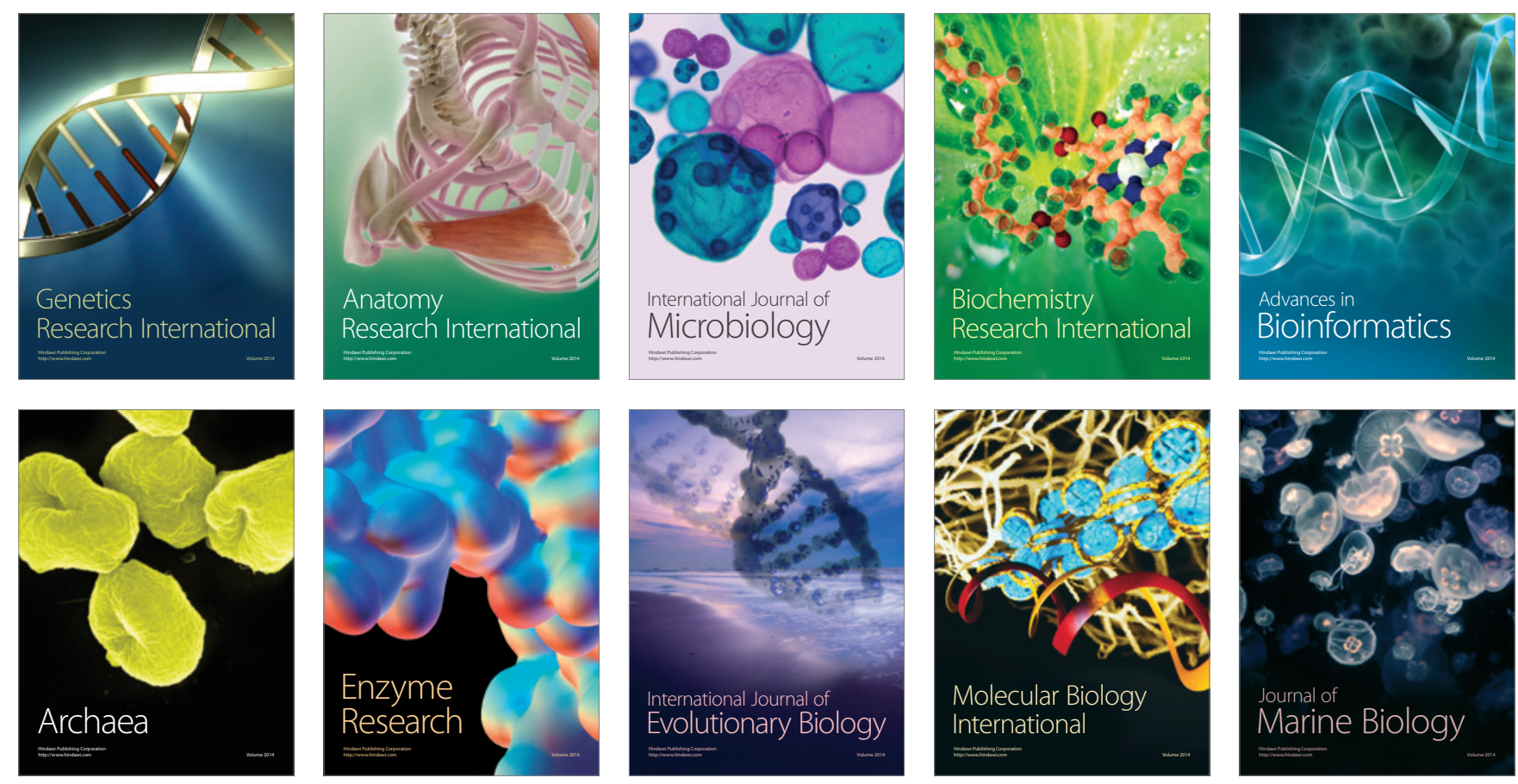